\title{
Optimization of friction and wear characteristics of varied cryogenically treated hot die steel grade AISI-H13 under dry condition
}

\author{
Sanjeev KATOCH ${ }^{1,2, *}$, Rakesh SEHGAL ${ }^{3}$, Vishal SINGH ${ }^{1}$ \\ ${ }^{1}$ Centre for Materials Science and Engineering, National Institute of Technology, Hamirpur (HP) 177005, India \\ ${ }^{2}$ Institute for Auto Parts \& Hand Tools Technology, A-9, Phase V, Focal Point, Ludhiana (Punjab) 141010, India \\ ${ }^{3}$ Department of Mechanical Engineering, National Institute of Technology, Hamirpur (HP) 177005, India \\ Received: 30 May 2016 / Revised: 07 September 2016 / Accepted: 11 December 2016 \\ (C) The author(s) 2017. This article is published with open access at Springerlink.com
}

\begin{abstract}
Cryogenic treatment (CT) is a relatively new field, which has emerged during the last three decades of the twentieth century. However, its impact on material shaping and making tool life, and enhancement of their mechanical properties are quite remarkable. The selection of appropriate process parameters for CT is essential for cost reduction and optimum productivity. This study focuses on the influence of key parameters of CT cycles (i.e., soaking temperature and duration) on the friction and wear behavior of AISI H13 hot die steel under dry sliding conditions against hardened and tempered AISI D3 cold work tool steel (counter face) at varying sliding speeds and loads. Mathematical models have been developed for wear rate, the average coefficient of friction, and maximum contact temperature using the Box-Cox methodology. The developed mathematical models have been validated by comparing with the experimental results. Moreover, the optimum values of the process parameter have been employed to maximize the output and validate the same by confirmation of the experiments. To the best of our knowledge, this is the first study that demonstrates the modeling and optimization of sliding friction and wear characteristics of AISI H13 under varied CT cycles.
\end{abstract}

Keywords: cryogenics treatment; hot die steel; friction; wear; modeling; Box-Cox method; optimization

\section{Introduction}

Tools and dies used for the mass production of the material forming and shaping industries do not last forever because they wear out either by the steady growth of wear flats or by the accumulation of cracks, which lead to fractures. Consequently, the tool and die failure cause a sudden disruption, causing a delay in the production schedule. Apart from the lifetime of tools and dies, the replacement cost of worn tools (consumable cost) and the time to replace worn-out tools are significant in materials forming and shaping economics [1]. Indeed, a significant part of the improvement in the economic productivity of the components can be attributed to the use of long life tools and dies. Therefore, to further enhance efficiency and reduce costs in its operation, it is necessary to improve the tool and die materials used. AISI H13 is hot die steel (HDS) used for forging dies, inserts, punches, molds for die casting of aluminum, zinc, and magnesium. Nowadays, one of the latest techniques used in the industry to enhance the materials physical and mechanical properties is cryogenic treatment (CT). In contrast to the surface treatment in $\mathrm{CT}$, the bulk properties of the materials as well as the surface properties are affected and its effects are permanent [2]. Moreover CT enhances the mechanical properties of tools and their life-span [3]. Several researchers

* Corresponding author: Sanjeev KATOCH, E-mail: katochsanjeev@gmail.com 


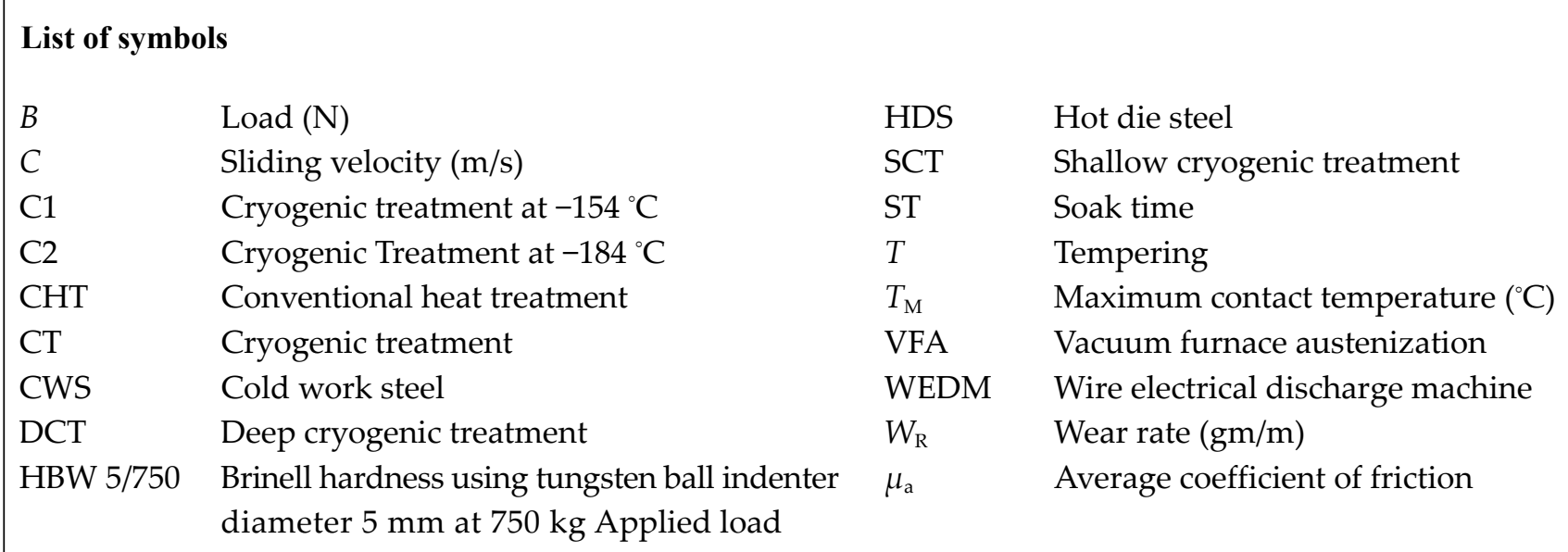

have cited the worthiness of $\mathrm{CT}$ and its influence on the modification of the morphology of microstructures and enhancement in hardness of the CWS and HDS [4-7].

Tribological behavior of CWS 80CrMo12 5 was examined by Amini et al. [8] at different cryo-treatment holding times (i.e., 0, 6, 24, 48, 72, and $168 \mathrm{~h}$ ); sliding velocity: $0.1,0.15$, and $0.2 \mathrm{~m} / \mathrm{s}$; load: $120 \mathrm{~N}$ and $160 \mathrm{~N}$; up to $1,000 \mathrm{~m}$. They concluded that $48 \mathrm{~h}$ soaking time at deep cryogenic temperature is optimum to achieve maximum wear resistance. Das et al. [9] demonstrated the influence of varied cryo-treatment on dry sliding wear behavior of AISI D2 CWS at different holding times (i.e., 0, 12, 36, 60, and $84 \mathrm{~h}$ ) at different operating parameters of load and sliding velocity in a pinon-disk wear test. They suggested that at DCT $36 \mathrm{~h}$ is optimum soaking time to achieve maximum wear resistance for AISI D2 CWS.

The wear resistance study of cryogenically treated (treatment temperature of $-145{ }^{\circ} \mathrm{C}$ and soaking times of 12, 24, 36, 48, and $60 \mathrm{~h}$ ) AISI 52100 bearing steel at a load of $10-20 \mathrm{~N}$ and sliding velocity of $0.15 \mathrm{~m} / \mathrm{s}$, using the ball-disk arrangement was carried out by Gunes et al. [10]. They claimed that $36 \mathrm{~h}$ was the optimal soaking time at the DCT to enable better wear resistance and also reported that delamination wear occurred with micro cracks in the DCT samples.

Yong et al. [11] studied the effect of deep cryogenic treatment on tungsten carbide tools for turning. They found that cryogenically treated tools have increased wear resistance to chipping while performing continuous cutting for short periods of time. Chipping times achieved were 1.3 times longer than non-cryogenically treated tools. Cryogenically treated tools lose their wear resistance when exposed to prolonged periods of high temperature during continuous cutting. Firouzdor et al. [12] demonstrated that deep CT enhances the wear resistance and tool life of the M2 HSS drill when used for dry high-speed drilling of normalized CK 40 steel. Precipitation of fine spherical carbides (spherical carbides are Fe3 $\mathrm{M} 2,(\mathrm{M}=(\mathrm{W}$, $\mathrm{Mo}, \mathrm{Cr}, \mathrm{V}) \mathrm{C}$ ) as a result of cryogenic treatment is responsible for wear resistance improvement. The main reason for improving fine carbide precipitation is due to super-saturation of martensite with decreasing temperature, leading to lattice distortion and thermodynamic instability of martensite; therefore, both carbon and alloy elements migrate to the nearby defects and segregate there which results in the formation of fine carbides on the subsequent warming up or tempering. As per this study, diffusion wear was found as the dominant wear mechanism. Huang et al. [13] analyzed the effect of CT on M2 tool steel microstructures using TEM and XRD. The results showed that CT can facilitate the formation of carbon clustering and increase the carbide density, thereby improving the wear resistance of steels. Precipitation of fine spherical carbides (spherical carbides are Fe3 $\mathrm{M} 2,(\mathrm{M}=(\mathrm{W}, \mathrm{Mo}, \mathrm{Cr}, \mathrm{V}) \mathrm{C})$ because $\mathrm{CT}$ is responsible for wear resistance improvement. Retained austenite eliminates and fine-dispersed eta (ท́) carbide is precipitated.

It is evident from the literature review that due to the lack of visible changes on cryogenically treated 
materials and the absence of organized fundamental research on the CT process, skepticism prevailed in the industry about this promising material treatment technique.

Though some researchers studied the effects of CT on the wear behavior of tool steel, but till now no research studies have been reported to develop and validate the models or to optimize the sliding friction and wear characteristics of HDS AISI H13 under varied CT cycles. The benefits of CT on the tool and die materials can only be exploited to its full potential if the CT cycles are optimized for the different grades of the tools and die steels according to the desired application. In this work, we attempt to develop the models of friction and wear behavior of varied cryogenically treated (soaking temperature and soaking duration) HDS AISI H13 sliding against hardened and tempered CWS AISI D3 (counter face) at varying sliding speeds and loads on a multi-tribotester under dry conditions. Hence, the authors claim the novelty of this study.

Mathematical modeling equations for wear rate $\left(W_{\mathrm{R}}\right)$, average coefficient of friction, and maximum contact temperature of varied cryogenically treated HDS AISI H13 are developed using the Box-Cox method of the response surface methodology (RSM) technique. To find the optimized conditions, the desirability function approach has been used to maximize the output parameter. In the sheet metal industry, HDS AISI H13 is used as a die for punching operations as well as for flash cutting in forging operations with CWS AISI D3 as the punch. This pair faces strong challenges regarding wear resistance in practical conditions. Hence, the HDS-CWS pair is selected for this experimental study. The counter-face material has higher hardness than the selected HDS.

\section{Materials and methods}

The AISI H13 material in the shape of round bars of diameter $16 \mathrm{~mm}$ and in the spheroidized annealed condition was used for this study. The chemical composition of the material was confirmed with the optical spark emission Spectrometer (DV6, Baird, USA), following ASTM E 415-2014 standards [14] and given in Table 1.

The hardness of the received material was checked with the calibrated optical Brinell hardness tester (B-3000(O), Saroj, India), using the Tungsten carbide ball of diameter $5 \mathrm{~mm}$ at $750 \mathrm{~kg}$ load with a dwell time of $15 \mathrm{~s}$, as per the ASTM E 10-2008 standards [16]. The hardness of the received material is found to be in the range of $167-170$ HBW $5 / 750$. Blocks of $6.35 \mathrm{~mm} \times 6.35 \mathrm{~mm} \times 9 \mathrm{~mm}$ were machined from round bars using WEDM Make: Charmilles Tech. Switzerland in the longitudinal direction of received HDS AISI H13, as per the ASTM G 77-05 RA 2010 standards [17]. Vacuum heat treatment of machined samples was performed in the horizontal front loading electrically heated vacuum furnace (Hind High Vacuum, Bangalore, India, and capacity: $600 \mathrm{~mm} \times 600 \mathrm{~mm} \times 900 \mathrm{~mm}$ ), at a vacuum level maintained to $10^{-2} \mathrm{mbar}$, austenization temperature of $1,040{ }^{\circ} \mathrm{C}$, soak time at austenization temperature of $30 \mathrm{~min}$, nitrogen gas quench to $27^{\circ} \mathrm{C}$ at a gas pressure of 5 bar. Table 2 provides the details of the sample treatment condition and nomenclature. After the quenching samples were taken out from the furnace and divided into three groups, namely A3T: vacuum heat treated and three times tempered for $2 \mathrm{~h}, \mathrm{C} 1$ : vacuum heat treated plus cryogenic treated at $-154{ }^{\circ} \mathrm{C}$ for varied soak times of 6,21 , and $36 \mathrm{~h}$ and tempered for $2 \mathrm{~h}, \mathrm{C} 2$ : vacuum heat treated plus cryogenic treated at $-184^{\circ} \mathrm{C}$ for varied soak times of 6 , 21 , and $36 \mathrm{~h}$ and tempered for $2 \mathrm{~h}$. The A3T group samples of HDS H13 were tempered at 550, 570 and $620{ }^{\circ} \mathrm{C}$ respectively for $2 \mathrm{~h}$, coded as $\mathrm{H} 13 \mathrm{~A} 3 \mathrm{~T}$, in a box-type electrically heated furnace, with a capacity of $300 \mathrm{~kg}$, and a temperature range up to $750{ }^{\circ} \mathrm{C}$. The $\mathrm{C} 1$ and $\mathrm{C} 2$ group samples of both grade materials were deeply, cryogenically treated at $-154{ }^{\circ} \mathrm{C}$ and

Table 1 Chemical composition of HDS steel grade AISI H13 in weight \% [15].

\begin{tabular}{ccccccccccccc}
\hline Element & $\% \mathrm{C}$ & $\% \mathrm{Si}$ & $\% \mathrm{Mn}$ & $\% \mathrm{P}$ & $\% \mathrm{~S}$ & $\% \mathrm{Ni}$ & $\% \mathrm{Cr}$ & $\% \mathrm{Mo}$ & $\% \mathrm{~V}$ & $\% \mathrm{Co}$ & $\% \mathrm{~W}$ \\
\hline Observed value & 0.39 & 0.88 & 0.32 & 0.018 & 0.007 & 0.04 & 5.00 & 1.27 & 0.93 & 0.01 & 0.18 \\
& & & & & & & & \\
Specified value & $\begin{array}{c}0.32 \text { to } \\
0.45\end{array}$ & $\begin{array}{c}0.80 \text { to } \\
1.20\end{array}$ & $\begin{array}{c}0.20 \text { to } \\
0.50\end{array}$ & $0.030 \mathrm{Max}$ & $0.030 \mathrm{Max}$ & $0.30 \mathrm{Max}$ & $\begin{array}{c}4.75 \\
\text { to } 5.50\end{array}$ & $\begin{array}{c}1.10 \text { to } \\
1.75\end{array}$ & $\begin{array}{c}0.80 \text { to } \\
1.20\end{array}$ & - & - \\
\hline
\end{tabular}


Table 2 Heat treatment sequence followed for HDS H13.

\begin{tabular}{|c|c|c|}
\hline No. & Nomenclature & Depiction of treatment \\
\hline 1 & A $3 \mathrm{~T}$ & $\begin{array}{l}\mathrm{VFA}=1,040{ }^{\circ} \mathrm{C}, \mathrm{ST}=30 \mathrm{~min} \text {, nitrogen gas quench, quench pressure }=5 \mathrm{bar} \text {, three } T=550{ }^{\circ} \mathrm{C}, 570{ }^{\circ} \mathrm{C}, 620^{\circ} \mathrm{C} \\
\text { respectively for } 2 \mathrm{~h} .\end{array}$ \\
\hline 2 & A T C1(6)T & $\begin{array}{l}\text { VFA }=1,040{ }^{\circ} \mathrm{C}, \mathrm{ST}=30 \mathrm{~min} \text {, nitrogen gas quench, quench pressure }=5 \mathrm{bar}, T=550{ }^{\circ} \mathrm{C} \text { for } 2 \mathrm{~h}, \mathrm{C} 1, \mathrm{ST}=6 \mathrm{~h} \text {, } \\
T=620^{\circ} \mathrm{C} \text { for } 2 \mathrm{~h} .\end{array}$ \\
\hline 3 & AT C1(21)T & $\begin{array}{l}\text { VFA }=1,040{ }^{\circ} \mathrm{C}, \mathrm{ST}=30 \mathrm{~min} \text {, nitrogen gas quench, quench pressure }=5 \text { bar, } T=550{ }^{\circ} \mathrm{C} \text { for } 2 \mathrm{~h}, \mathrm{C} 1, \mathrm{ST}=21 \mathrm{~h} \text {, } \\
T=620^{\circ} \mathrm{C} \text { for } 2 \mathrm{~h} .\end{array}$ \\
\hline 4 & AT C1(36)T & $\begin{array}{l}\text { VFA }=1,040{ }^{\circ} \mathrm{C}, \mathrm{ST}=30 \mathrm{~min} \text {, nitrogen gas quench, quench pressure }=5 \mathrm{bar}, T=550{ }^{\circ} \mathrm{C} \text { for } 2 \mathrm{~h}, \mathrm{C} 1, \mathrm{ST}=36 \mathrm{~h} \text {, } \\
T=620^{\circ} \mathrm{C} \text { for } 2 \mathrm{~h} .\end{array}$ \\
\hline 5 & AT C2(6)T & $\begin{array}{l}\text { VFA }=1,040{ }^{\circ} \mathrm{C}, \mathrm{ST}=30 \mathrm{~min} \text {, nitrogen gas quench, quench pressure }=5 \mathrm{bar}, T=550{ }^{\circ} \mathrm{C} \text { for } 2 \mathrm{~h}, \mathrm{C} 2, \mathrm{ST}=6 \mathrm{~h} \text {, } \\
T=620^{\circ} \mathrm{C} \text { for } 2 \mathrm{~h} .\end{array}$ \\
\hline 6 & AT C2(21)T & $\begin{array}{l}\text { VFA }=1,040{ }^{\circ} \mathrm{C}, \mathrm{ST}=30 \mathrm{~min} \text {, nitrogen gas quench, quench pressure }=5 \mathrm{bar}, T=550{ }^{\circ} \mathrm{C} \text { for } 2 \mathrm{~h}, \mathrm{C} 2, \mathrm{ST}=21 \mathrm{~h} \text {, } \\
T=620^{\circ} \mathrm{C} \text { for } 2 \mathrm{~h} .\end{array}$ \\
\hline 7 & AT C2(36)T & $\begin{array}{l}\text { VFA }=1,040{ }^{\circ} \mathrm{C}, \mathrm{ST}=30 \mathrm{~min} \text {, nitrogen gas quench, quench pressure }=5 \mathrm{bar}, T=550{ }^{\circ} \mathrm{C} \text { for } 2 \mathrm{~h}, \mathrm{C} 2, \mathrm{ST}=36 \mathrm{~h} \text {, } \\
T=620^{\circ} \mathrm{C} \text { for } 2 \mathrm{~h} .\end{array}$ \\
\hline
\end{tabular}

* Number in parentheses show the soaking times in $\mathrm{h}$ at the cryogenic temperature.

$-184^{\circ} \mathrm{C}$, respectively, for varied soak times of 6,21 , and $36 \mathrm{~h}$, with pre- and post-tempering at two different temperatures.

Varied CT was performed in a computer-controlled cryogenic processor with a tempering facility up to $150{ }^{\circ} \mathrm{C}$ (Make: Primero Enserve, Chennai, India). To maintain the stresses at a minimum level and to avoid thermal soaking of the material due to the abrupt temperature gradient of the case and core of the material, the slow cooling rate $\left(1^{\circ} \mathrm{C} / \mathrm{min}\right)$ from ambient to deep CT soak temperature and a slow heating rate $\left(1{ }^{\circ} \mathrm{C} / \mathrm{min}\right)$ from cryo-treatment soak temperature to ambient temperature were selected.

A hardened CWS AISI D3 roller with the following dimensions: outer diameter $=60 \mathrm{~mm}$, inner diameter $=$ $25 \mathrm{~mm}$, and thickness $=20 \mathrm{~mm}$, was used as the counter-face material. This roller was hardened and tempered to a hardness of $52 \mathrm{HRc}$ and its surface roughness was maintained at $\mathrm{Ra}<0.2 \mu \mathrm{m}$. The schematic of the wear test setup is shown in Fig. 1. Block-on-ring dry sliding wear tests were performed to assess the $W_{R}$, as per the ASTM standards designation G77-05 (Reapproved 2010) [17] using a multi-tribotester (Model: TR-30-M4, Make: DUCOM Instrument Pvt. Ltd. Bangalore, India). To attain the surface roughness in the range of $0.152-0.305 \mu \mathrm{m}$, faces of the blocks were grounded manually using silicon carbide emery paper of different grit sizes: 100, 220, $800,1,000,1,200$, and $1,400 \mu \mathrm{m}$ and finely polished

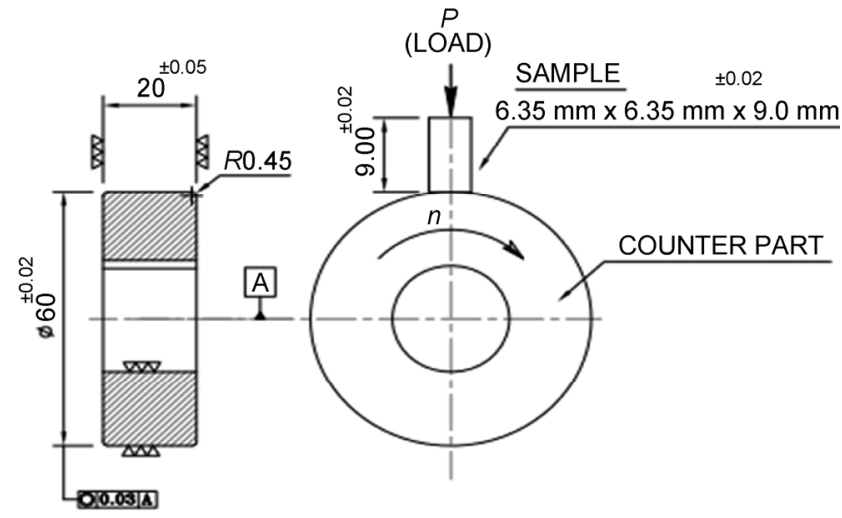

SECTION 'AA'

Fig. 1 Schematic presentation of the block on the ring wear test.

using a diamond slurry of grit size $6 \mu \mathrm{m}$ with white kerosene oil as a suspension media on a rotating velvet cloth. Samples were cleaned in hexane prior to the wear test. The gap between the static block sample and the counter face of the roller was maintained as $2 \mathrm{~mm}$ for each experiment. After each test roller was polished using a silicon carbide emery paper of different grit sizes: 100, 400 and 1,000 $\mu \mathrm{m}$ they were then cleaned with hexane solution to maintain the average surface $(\mathrm{Ra}<0.2 \mu \mathrm{m})$. Before and after each experiment, the weight of the samples were measured using a precision electronic analytical balance (Model: HM-200, Make: A\&D) with an accuracy of $0.00001 \mathrm{gm}$ to calculate the weight loss. A non-contact type infrared thermometer (TFI20; Ebro; accuracy: $\pm 2.5 \%$ or $2.5^{\circ} \mathrm{C}$; 
resolution: $0.2{ }^{\circ} \mathrm{C}$; measuring range: $-30{ }^{\circ} \mathrm{C}$ to $180{ }^{\circ} \mathrm{C}$ ) was used to measure the contact temperature at the junction of the sample and the counter face.

The experiments were carried out using normal load and sliding velocity in the range of $60-140 \mathrm{~N}$ and $0.628-1.885 \mathrm{~m} / \mathrm{s}$, respectively, in dry sliding conditions to measure the $W_{R}$ and coefficient of friction. The $W_{R}$ of each block was calculated from the weight loss, and each test was repeated three times for each condition to obtain the average value of weight loss. The duration of each experiment was $300 \mathrm{~s}$. A comparison of the varied CT with respect to CHT has been made to identify its effects on the tribological behavior. Investigation of the tribological behavior in a range of parameters at various levels was carried out for the conventional and varied cryogenically treated samples at: (a) varying levels of cryogenic soak temperature (i.e., $-155^{\circ} \mathrm{C}$ and $-184{ }^{\circ} \mathrm{C}$ ), and (b) varying levels of cryogenic soak time (i.e., 6, 21, and $36 \mathrm{~h}$ ). The wear test of conventional and varied cryogenically treated samples was performed using the full factorial design of the experiment. Levels of the input parameter for the wear test experiments are shown in Table 3. Machine capabilities were taken into consideration while selecting the test parameters.

A total of 175 experimental runs were conducted.
The average of three replicate values of each run was taken as the dependent variable, or response, or yield $\left(W_{R}\right.$, average coefficient of friction, and maximum contact temperature) to account for experimental errors. The experimental design was created with DesignExpert 7.1 (Stat-Ease, USA), using the full factorial design of experiments. This experiment design allows one to study the effect of each factor on the response variables, as well as their interaction with each other. To study the main and interaction effects of one categorical and two numeric factors on the response parameter, a statistical analysis of variance (ANOVA) was performed. To identify whether the factors are significant or not, an F-test in ANOVA was used, where higher $F$-values indicate that a factor has higher influence on the process.

Microhardness values $\left(\mathrm{HV}_{1}\right)$ were obtained for A3T, ATC1(6)T, ATC1(21)T, and ATC1(36)T AISI H13 HDS at five equally spaced points along the diagonal length of each specimen using the micro Vicker hardness tester (Model: MVK-H2, Make: Akashi), by following the ASTM E384-08a standards [18]. Table 4 depicts the results of the mean micro-hardness values along with their corresponding standard deviation and standard error of mean.

Figure 2 shows the FESEM micrograph photo of the

Table 3 Experimental variables and their different levels used for the block-on-ring dry sliding wear tests as input parameters.

\begin{tabular}{|c|c|c|c|c|c|c|c|c|c|}
\hline Code & Factor & Unit & \multicolumn{7}{|c|}{ Levels values } \\
\hline A & Treatment Type & - & A3T & $\operatorname{ATC1}(6) \mathrm{T}$ & $\operatorname{ATC} 1(21) \mathrm{T}$ & $\mathrm{ATC1}(36) \mathrm{T}$ & ATC2(6)T & ATC2(21)T & ATC2(36)T \\
\hline & Treatment Temperature & ${ }^{\circ} \mathrm{C}$ & & & -154 & & & -184 & \\
\hline $\mathrm{B}$ & Load & $\mathrm{N}$ & & 60 & & 80 & 100 & 120 & 140 \\
\hline $\mathrm{C}$ & Sliding Speed & $\mathrm{m} / \mathrm{s}$ & & 0.628 & & 0.942 & 1.257 & 1.571 & 1.885 \\
\hline
\end{tabular}

Table 4 Mean micro-hardness of CHT and varied cryogenic treated samples.

\begin{tabular}{cccc}
\hline $\begin{array}{c}\text { Treatment } \\
\text { Condition }\end{array}$ & $\begin{array}{c}\text { Mean micro- } \\
\text { hardness }\left(\mathrm{HV}_{1}\right)\end{array}$ & $\begin{array}{c}\text { Standard } \\
\text { deviation }\end{array}$ & SE of mean \\
\hline A3T & 450.2 & 5.06 & 2.26 \\
ATC1(6)T & 464.4 & 4.61 & 2.06 \\
ATC1(21)T & 443.4 & 4.21 & 1.88 \\
ATC1(36)T & 433.6 & 3.57 & 1.6 \\
ATC2(6)T & 452.1 & 4.90 & 2.19 \\
ATC2(21)T & 434.8 & 6.37 & 2.85 \\
ATC2(36)T & 426.4 & 4.03 & 1.80 \\
\hline
\end{tabular}

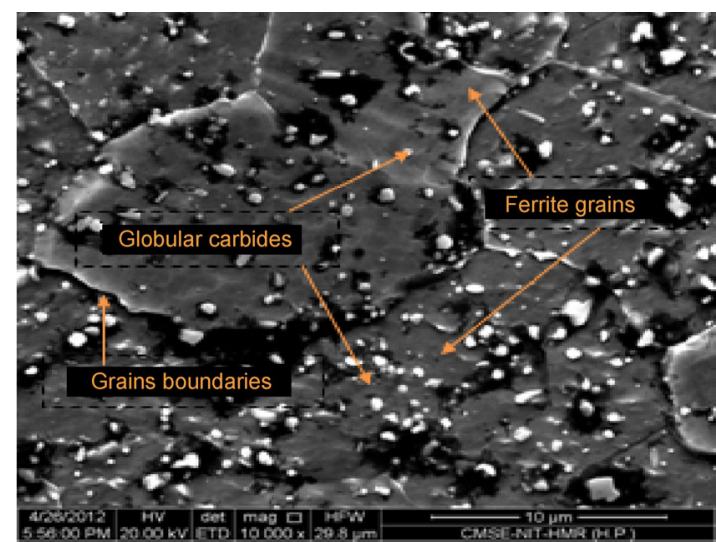

Fig. 2 FESEM micrograph photo of AISI H13 steel in the received condition. 
material before the treatment. It depicts the globular carbides in the matrix of ferrite [19]. The microstructure of the received material indicates that the material is in an annealed condition which is necessary for the machining operation to prepare the samples.

The micrograph photo of the material after the treatment is shown in Fig. 3, which clearly shows the even distribution of the precipitated fine secondary globular carbide in the matrix of tempered martensite. Moreover, the results are in concurrence with previous studies $[5,9,11]$ that reported the enhancement of numerous secondary carbides and the formation of homogenous carbides, which is responsible for the strengthening of the matrix, load bearing capacity, and wear resistance of tools and dies.

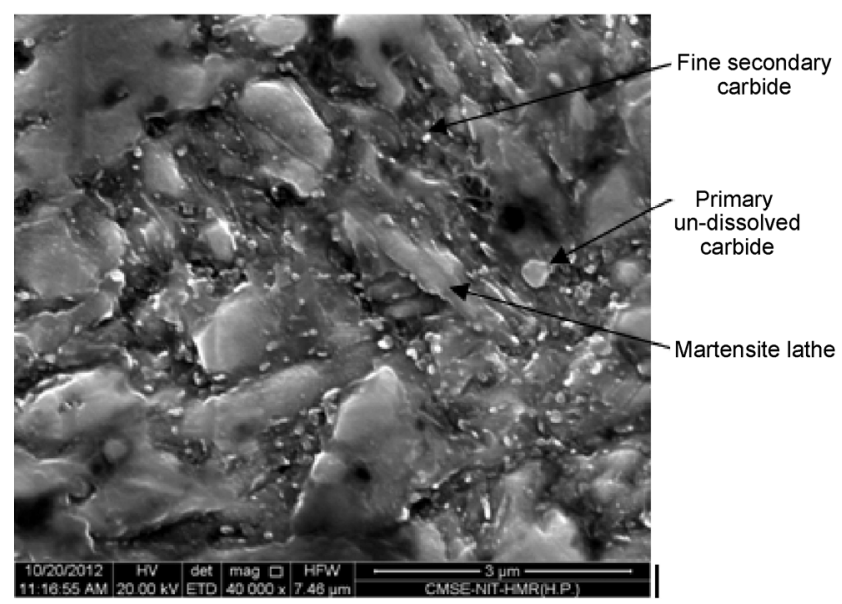

Fig. 3 FESEM image of the cryogenic treated sample of AISI-H13.

\section{Results and discussion}

The collection of experimental data for the dependent variable, or response $\left(W_{R}\right.$, average coefficient friction, and rise in maximum contact temperature) permits the estimation of all main and interaction effects. Response surface methodology (RSM) was used to optimize the experiment variables that produce desirable values of the response. The results and discussion are divided between the following sections:

\subsection{Evaluation of $W_{\mathrm{R}}$ at dry sliding conditions for AISI-H13}

Figure 4 shows the normal plot of residuals distribution and illustrates that the residuals follow a normal distribution, as residuals follow a straight line except a few are scattered at the upper and lower ends. Diagnosis of the internally studentized residuals versus the experimental run order in the case of $W_{R}$ is shown in Fig. 5. The studentized residuals method is commonly used to detect discrepant data and is defined as the residual divided by the estimated standard deviation of that residual. Figure 5 gives the residuals versus run order plot. It presents the random scatter in the range of \pm 3 standard deviations and all points are well fitted in the model. To determine the outlier data or values which are not easily predicted by the model, diagnosis of the response value as a function of the predicted response value in the case of $W_{R}$ is performed.

Figure 6 represents the actual versus the predicted response values in the case of $W_{R}$ at the dry sliding condition. It indicates the adequacy of the model over the range of data; as all the data points are scattered about the $45^{\circ}$ diagonal reference line. The line just

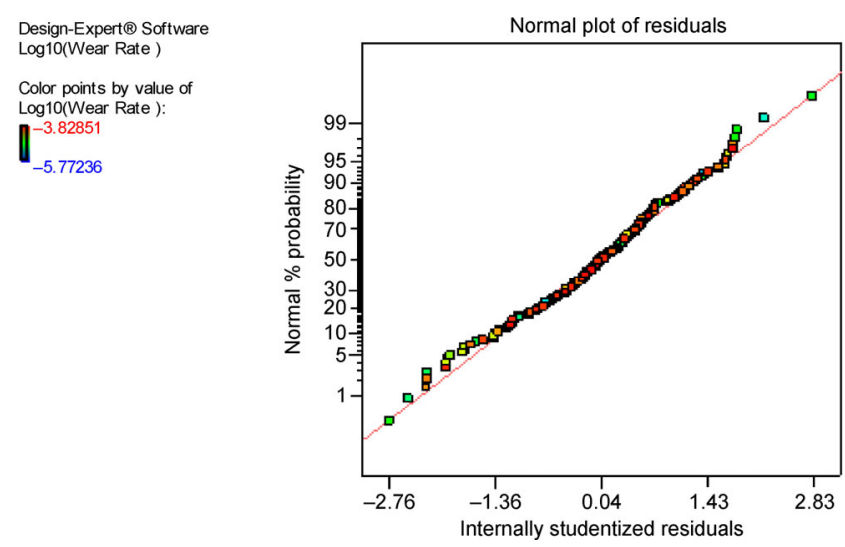

Fig. 4 Normal plot of residuals for $W_{\mathrm{R}}$.

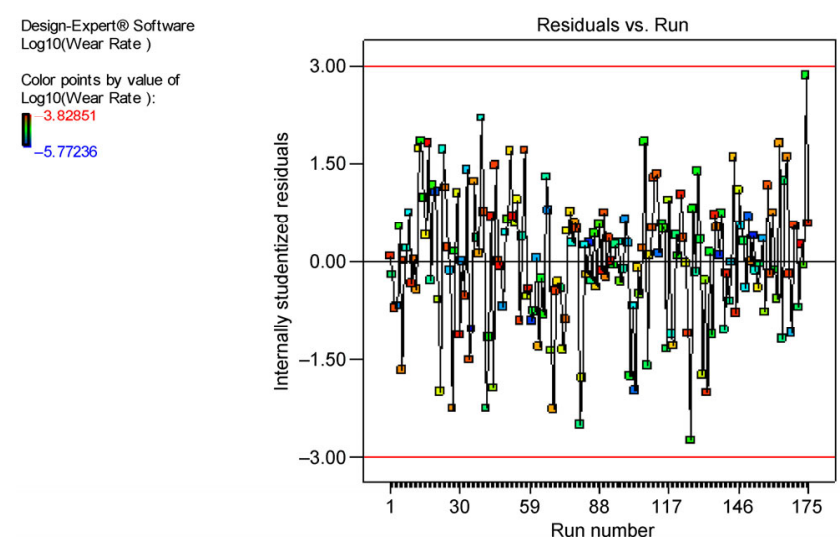

Fig. 5 Distribution of residuals over the experimentation run order for $W_{\mathrm{R}}$. 


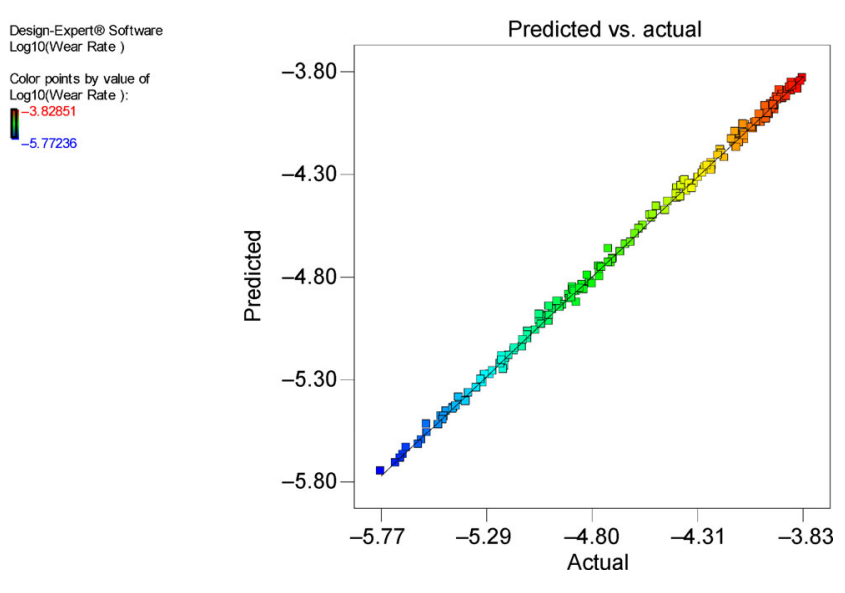

Fig. 6 Predicted versus actual response values for $W_{\mathrm{R}}$.

passes through the middle of the data over a whole range of the data. In this case, the response of $W_{R}$ to the input variables varies from the minimum value of $1.69 \times 10^{-5}$ to $1.48 \times 10^{-4}$. The ratio of maximum to minimum in this case (87.87) is greater than the threshold limit of 10; this indicates that the transformation may be desirable. The normality of the process can always be improved by stabilizing the variance, which can be performed by the transformation.

To obtain a simple, normal, linear model that satisfies the aims of homogeneity of variance and normality data, the Box-Cox method was used to determine the power transformation for the dependent variable. Figure 7 shows the Box-Cox plot obtained using Design-Expert 7.1 software within \pm 3 standard deviations. The legend information on the left of Fig. 7 indicates that the minimum in $\operatorname{Ln}$ (Residual SS) occurs when $\lambda=0.0$, the best $\lambda$ value indicated in the plot by the long vertical (green line) at the center of the U-shaped curve. The point where the solid horizontal line cuts the U-shaped curve (identified by short pink lines) defines the upper and lower 95\% confidence interval limit for the best $\lambda$ value. The interval is $-0.03<\lambda<0.03$ and does not include $\lambda=1$ (Fig. 7), thus ensuring that transformation will be helpful. The maximum likelihood estimate of $\lambda$ is that value of $\lambda$ which minimizes the error sum of squares of the fitted model. Design-Expert 7.1 recommends the $\log$ transformation $(\lambda=0)$ for the best fit of the model. The short vertical line (blue line) in Fig. 7 indicates the current transformation, which is the best-suggested transformation at $\lambda=0$.
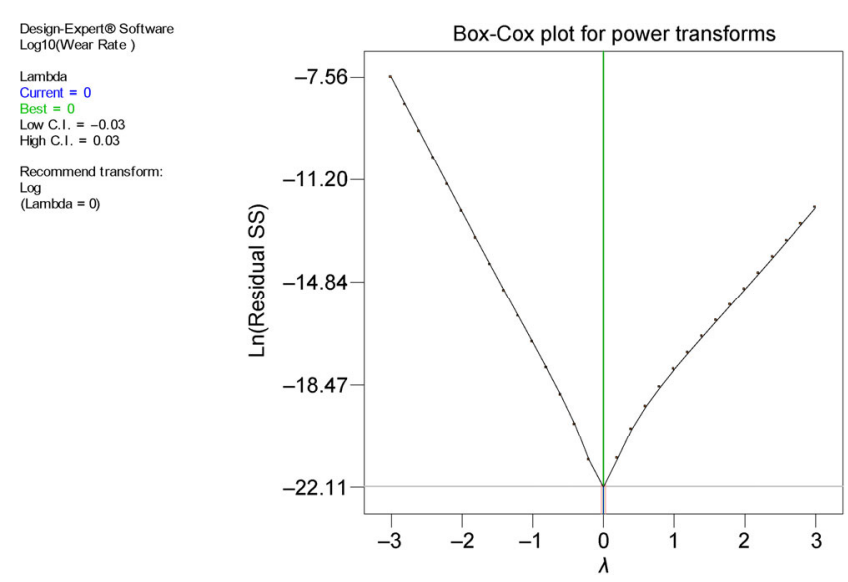

Fig. 7 Box-Cox plot for power transformation in the case of $W_{\mathrm{R}}$.

The selection of the model for the analysis is carried out using the data of coefficient of determination of the regression (R-squared). The R-squared values of data for different models obtained using DesignExpert 7.1 software are shown in Table 5. The "R-squared" values near to 1 , always indicate that a regression line fits the data well. The suggested model for the data is cubic, with the "adjusted R-squared" value of 0.9986 , "predicted R-Squared" value of 0.9981 and the $\mathrm{p}$-value (Prob $>$ F) $<0.0001$.

After the elimination of all insignificant terms, ANOVA is modified manually by choosing the significant terms as shown in Table 6 . In the new model, the overall $F$-test value is improved to $8,780.09$ and remains significant with 13 degrees of freedom.

Therefore, the modified model has all the significant terms, i.e., $A, B, C, B C, B^{2}, C^{2}, B C^{2}$, and $C^{3}$. In the individual factors, the strongest influence on the $W_{R}$ is found to be of the sliding velocity (with highest $F$ value of 93,708.8), followed by load and treatment type. The significant influencing effect among the interaction is of $B C$ only. The values of different tests under coefficient of regression analysis are determined and compared, as shown in Table 7. The "predicted R-Squared" value of 0.9983 is in reasonable agreement with the "adjusted R-Squared" value of 0.9985 in this model. Adequate precision, "Adeq precision" measures the signal to noise ratio. The reduced cubic model has an Adeq precision of 311.77, which is better than the full cubic model, and much higher than the minimum required value of four. The model can be used to navigate the design space, where the log of 
Table 5 R-Squared values for different models in case of wear rate.

\begin{tabular}{ccccccc}
\hline Source & Standard deviation & R-squared & Adjusted R-squared & Predicted R-squared & PRESS & Remarks \\
\hline Linear & 0.14 & 0.9428 & 0.94 & 0.9363 & 3.45 \\
2FI & 0.12 & 0.9577 & 0.9518 & 0.945 & 2.97 \\
Quadratic & 0.12 & 0.961 & 0.9551 & 0.9486 & 2.78 \\
Cubic & 0.021 & 0.999 & 0.9986 & 0.9981 & 0.1 & Suggested \\
\hline
\end{tabular}

Table 6 Modified ANOVA for the case of $W_{\mathrm{R}}$.

\begin{tabular}{|c|c|c|c|c|c|c|}
\hline Source & Sum of squares & $\mathrm{DF}$ & Mean Square & $F$ value & p-value Prob $>F$ & Remarks \\
\hline Model & 53.98 & 13 & 4.15 & 8780.09 & $<0.0001$ & Significant \\
\hline$A$-type of treatment & 0.43 & 6 & 0.072 & 152.16 & $<0.0001$ & Significant \\
\hline$B$-load & 6.22 & 1 & 6.22 & 13142.7 & $<0.0001$ & Significant \\
\hline$C$-sliding velocity & 44.32 & 1 & 44.32 & 93708.7 & $<0.0001$ & Significant \\
\hline$B C$ & 0.8 & 1 & 0.8 & 1685.4 & $<0.0001$ & Significant \\
\hline$B^{2}$ & 0.11 & 1 & 0.11 & 239.04 & $<0.0001$ & Significant \\
\hline$C^{2}$ & 0.069 & 1 & 0.069 & 146.6 & $<0.0001$ & Significant \\
\hline$B C^{2}$ & 0.05 & 1 & 0.05 & 105.74 & $<0.0001$ & Significant \\
\hline$C^{3}$ & 1.99 & 1 & 1.99 & 4199.96 & $<0.0001$ & Significant \\
\hline Residual & 0.076 & 161 & $4.73 \mathrm{E}-04$ & & & \\
\hline Corrected total & 54.06 & 174 & & & & \\
\hline
\end{tabular}

Table 7 Values of coefficient for full and modified cubic models from ANOVA analysis.

\begin{tabular}{|c|c|c|c|}
\hline \multicolumn{2}{|c|}{ Full cubic model } & \multicolumn{2}{|c|}{ Reduced cubic model } \\
\hline Coefficient of regression & Value & Coefficient of regression & Value \\
\hline Standard deviation & 0.021 & Standard deviation & 0.022 \\
\hline Mean & -4.60 & Mean & -4.60 \\
\hline C.V. $\%$ & 0.45 & C.V. $\%$ & 0.47 \\
\hline PRESS & 0.10 & PRESS & 0.090 \\
\hline R-squared & 0.9990 & R-squared & 0.9986 \\
\hline Adjusted R-squared & 0.9986 & Adjusted R-squared & 0.9985 \\
\hline Predicted R-squared & 0.9981 & Predicted R-squared & 0.9983 \\
\hline Adeq precision & 184.323 & Adeq precision & 311.677 \\
\hline
\end{tabular}

$W_{\mathrm{R}}$ can be expressed by the following final regression equations:

\section{Type of treatment: A3T}

$\log _{10}\left(W_{\mathrm{R}}\right)=(-4.15+0.02 \times B-7.84 \times C+3.72 E-003 \times$ $B \times C-3.80 E-005 \times B^{2}+7.87 \times C^{2}-3.62 E-003 \times B \times$ $\left.C^{2}-2.02 \times C^{3}\right)$

\section{Type of treatment: ATC1(6)T}

$\log _{10}\left(W_{\mathrm{R}}\right)=(-4.19+0.02 \times B-7.84 \times C+3.72 E-$ $003 \times B \times C-3.80 E-005 \times B^{2}+7.87 \times C^{2}-3.62 E-003$

$\times B \times C^{2}-2.02 \times C^{3}$
Type of treatment: ATC1(21)T

$\log _{10}\left(W_{\mathrm{R}}\right)=(-4.23+0.016 \times B-7.84 \times C+3.72 E-003 \times$ $B \times C-3.80 E-005 \times B^{2}+7.87 \times C^{2}-3.620 E-003 \times B \times$ $\left.C^{2}-2.02 \times C^{3}\right)$

\section{Type of treatment: ATC1(36)T}

$\log _{10}\left(W_{\mathrm{R}}\right)=(-4.24+0.02 \times B-7.84 \times C+3.72261 E-$ $003 \times B \times C-3.80 E-005 \times B^{2}+7.87 \times C^{2}-3.62 E-003$

$\left.\times B \times C^{2}-2.02 \times C^{3}\right)$

Type of treatment: ATC2(6)T

$\log _{10}\left(W_{\mathrm{R}}\right)=(-4.27+0.01 \times B-7.84 \times C+3.72 E-003 \times$ 
$B \times C-3.80 E-005 \times B^{2}+7.87 \times C^{2}-3.62 E-003 \times B \times$ $\left.C^{2}-2.02 \times C^{3}\right)$

\section{Type of treatment: ATC2(21)T}

$\log _{10}\left(W_{\mathrm{R}}\right)=(-4.31+0.02 \times B-7.84 \times C+3.72 E-003 \times$ $B \times C-3.80 E-005 \times B^{2}+7.87 \times C^{2}-3.621770 E-003 \times$ $\left.B \times C^{2}-2.02 \times C^{3}\right)$

\section{Type of treatment: ATC2(36)T}

$\log _{10}\left(W_{\mathrm{R}}\right)=(-4.18+0.02 \times B-7.84 \times C+3.72 E-003 \times$
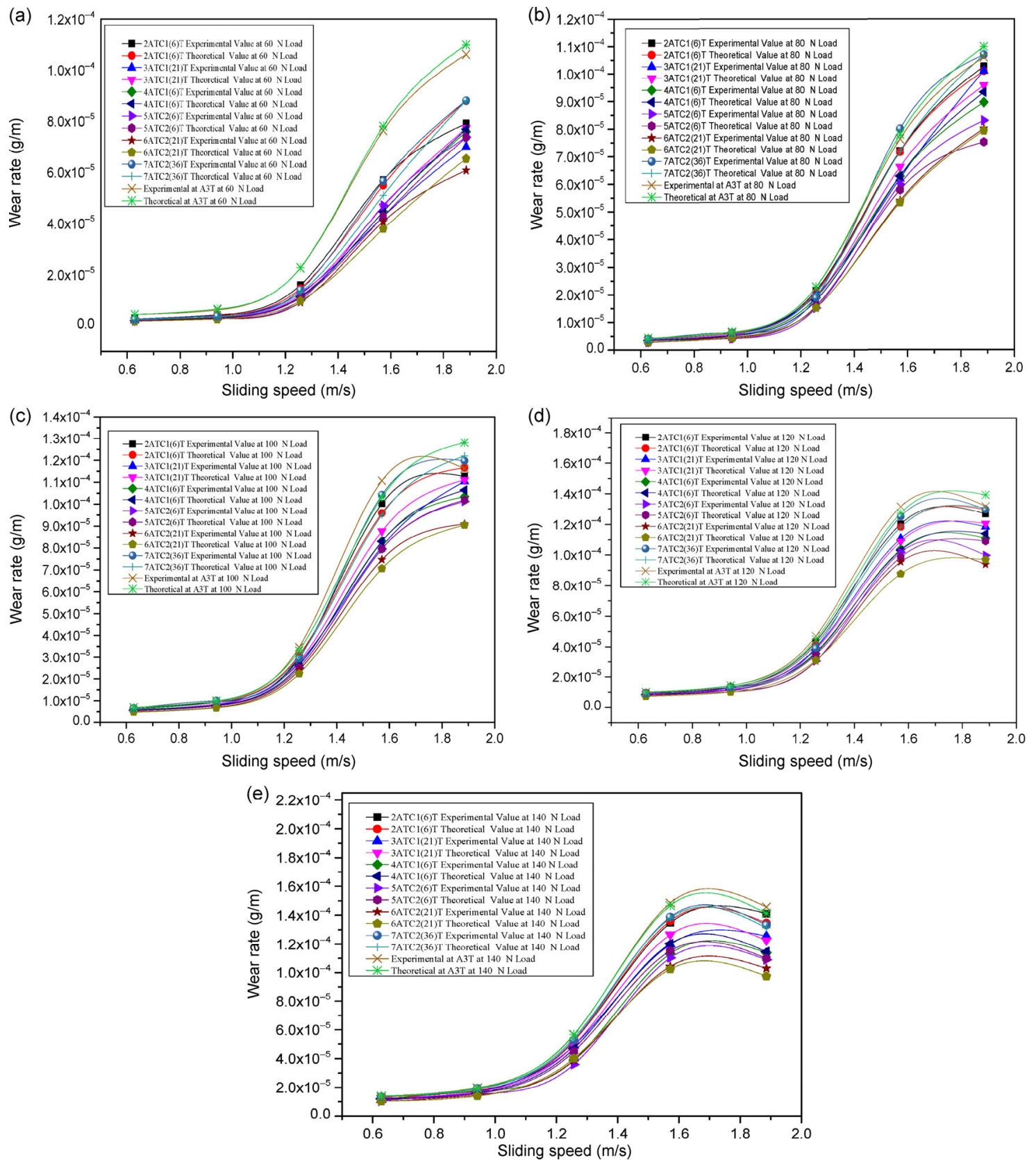

Fig. 8 Comparison of theoratical and experimental results for $W_{\mathrm{R}}$ at varying sliding speeds and loads: (a) $60 \mathrm{~N}$, (b) $80 \mathrm{~N}$, (c) $100 \mathrm{~N}$, (d) $120 \mathrm{~N}$, and (e) $140 \mathrm{~N}$ in the case of varied treatments: A3T, ATC1(6)T, ATC1(21)T, ATC1(36)T, ATC2(6)T, ATC2(21)T, and ATC2(36)T.
$B \times C-3.80 E-005 \times B^{2}+7.87 \times C^{2}-3.62 E-003 \times B \times$ $\left.C^{2}-2.02 \times C^{3}\right)$

The validation of Eqs. (1)-(7) is confirmed by comparing the trends of the experimental values of $W_{R}$ with the corresponding theoretical values obtained from the ANOVA analysis of the model (Fig. 8) at varying sliding speeds and loads. Figure 8 shows the similar experimental and theoretical results with an average maximum error of $9 \%$ in the corresponding

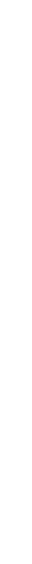


values. This confirms the validation of the model equations obtained for the $W_{R}$ from this analysis and is thus acceptable.

It is observed that at a sliding speed of $0.628 \mathrm{~m} / \mathrm{s}$ to $1.257 \mathrm{~m} / \mathrm{s}$, the $W_{R}$ increases slowly, after that a sharp increase in $W_{R}$ is evidenced at a sliding speed from $1.257 \mathrm{~m} / \mathrm{s}$ to $1.571 \mathrm{~m} / \mathrm{s}$ and it shows a decreasing trend at higher sliding speeds, i.e., $1.885 \mathrm{~m} / \mathrm{s}$ for selected loads $(60-140 \mathrm{~N})$ for conventionally treated and all types of cryogenic treated material under investigation.

The worn surfaces are shown in Fig. 9. Worn surfaces depict the fractured ridges, surface cracks, and deformation lips as well as wear debris in the shape of large chunks of metalic plates for all the treatment conditions. On the other hand, the sizes of the debris metal plates vary with the treatment conditions and operating parameter, i.e., sliding velocity and applied normal load. The size of the wear debris found in the case of the CHT group samples is more compared to the cryogenic treated samples. In the case of the sample which was subjected to the $36 \mathrm{~h}$ soak time, at the CT temperature displayed surface cracks, fractured ridges, deformation lips, and wear debris in the shape of metal sheets, indicative of delamination wear [20]. The severe plastic deformation of the samples (ATC2 (36) T) due to the lower hardness is indicated in Table 4.
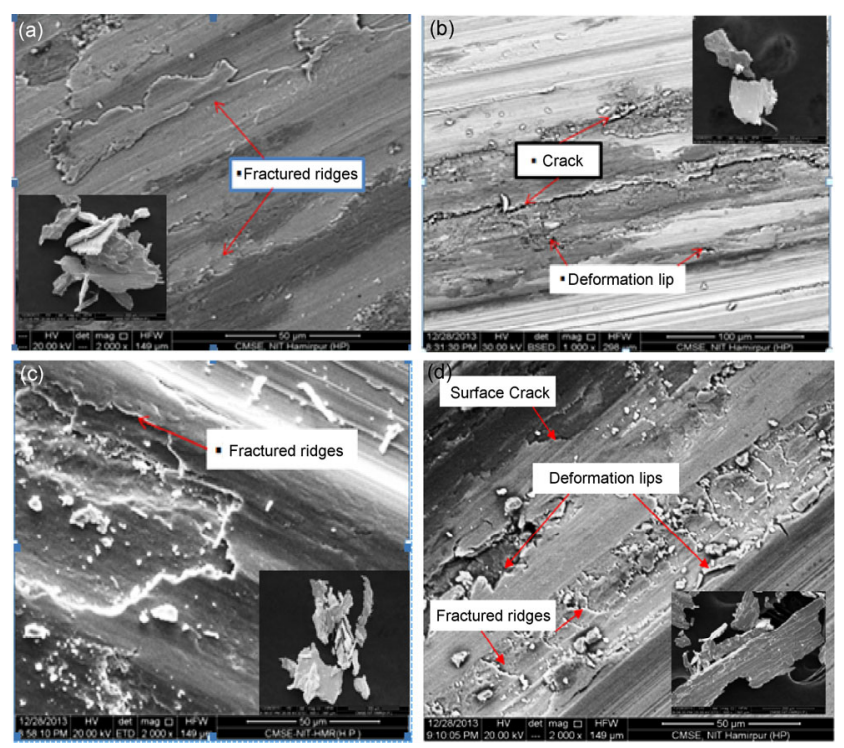

Fig. 9 FESEM micrograph photos of the worn surfaces generated under the wear test at a normal load of $140 \mathrm{~N}$ and sliding velocity of $1.885 \mathrm{~m} / \mathrm{s}$ for different treatments: (a) A3T, (b) $\mathrm{ATC1}(6) \mathrm{T}$, (c) ATC1(21)T, and (d) ATC1(36)T. Insets represent the wear debris generated in the respective sample.

\subsection{Evaluation of average coefficient of friction $\left(\mu_{\mathrm{a}}\right)$ at dry sliding condition for AISI-H13}

Figure 10 illustrates the analysis for the distribution of the residuals, and indicates that the residuals follow a normal distribution. Diagnosis of the internally studentized residuals versus the experimental run order in the case of the coefficient of friction, shown in Fig. 11, illustrates the random scatter in the range of \pm 3 standard deviations with all the points well fitted in the model. Thus, it proves the acceptability of the model and shows that the model satisfies the assumption for the ANOVA. The actual versus the predicted response values in the case of the average coefficient of friction are presented in Fig. 12, which depicts that the whole range of data points are scattered about the 45-degree diagonal reference line of the data. In this case, the response of the average coefficient of friction to the input variables varies from the minimum value of 0.17 to 0.22 . The ratio of

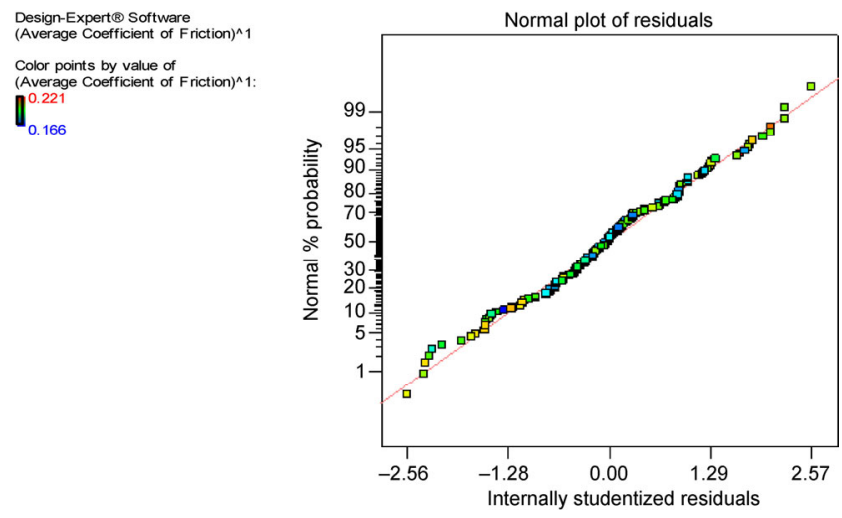

Fig. 10 Normal plot of residuals for the average coefficient of friction.
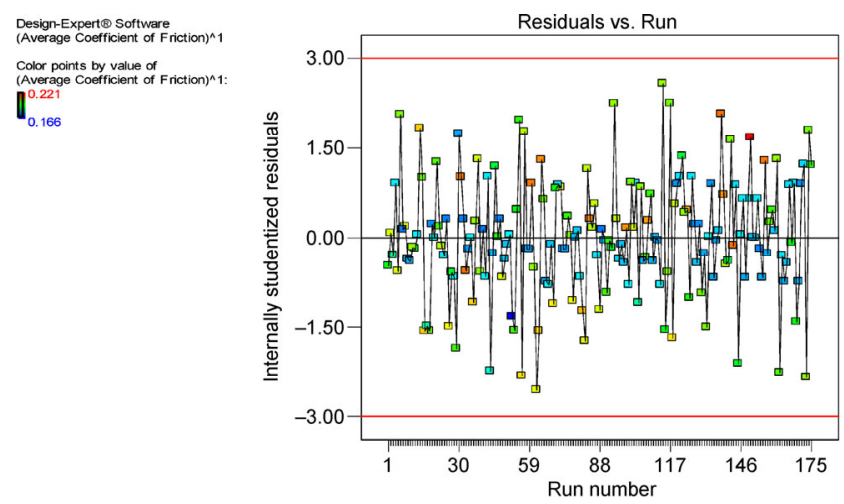

Fig. 11 Distribution of residuals over the experimentation run order for the average coefficient of friction. 


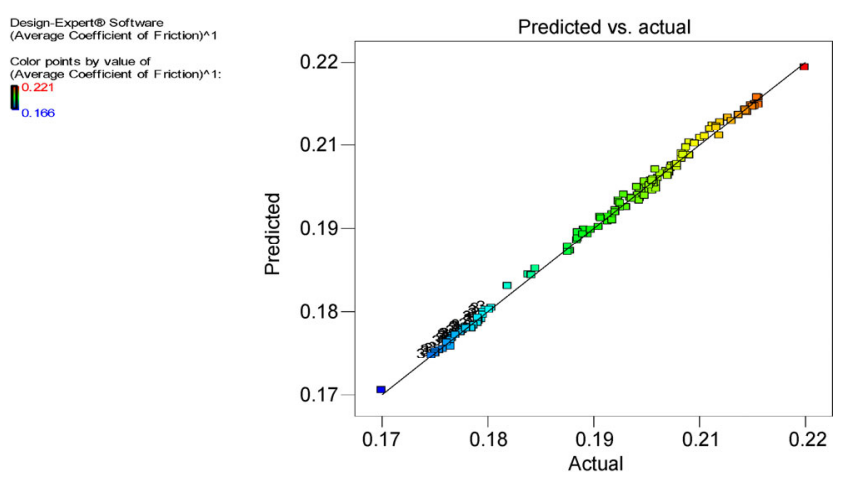

Fig. 12 Predicted versus actual response values for the average coefficient of friction.

maximum to minimum (1.33) is less than the threshold limit of 10, and thus it does not indicate the preference of transformation.

To further confirm this, the Box-Cox method is used to determine the power transformation for the dependent variable. Figure 13 shows the Box-Cox plot obtained using Design-Expert 7.1 software. The legend information on the left of Fig. 13 indicates that the minimum in $\operatorname{Ln}$ (Residual SS) occurs when $\lambda=-1.39$, the best $\lambda$ value is indicated in the graph by the long vertical (green line) at the center of the U-shaped curve. The point where the solid horizontal line cuts

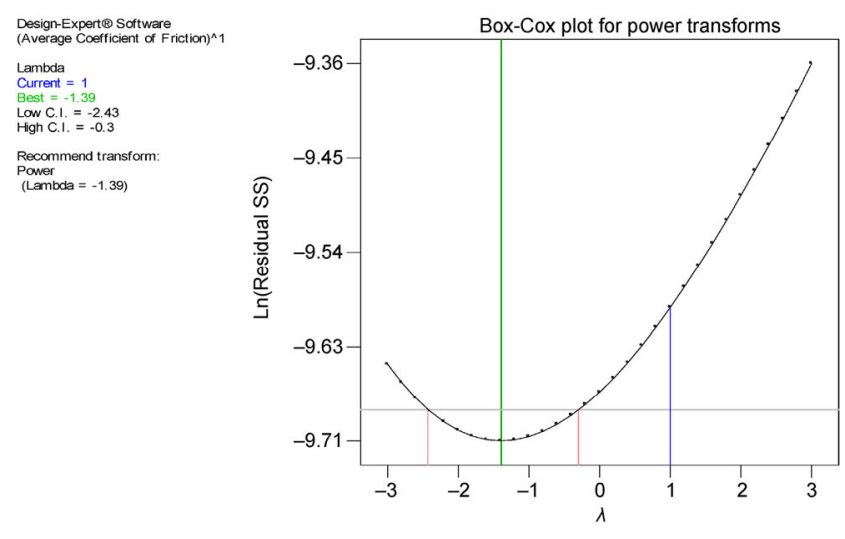

Fig. 13 Box-Cox plot for the average coefficient of friction. the U-shaped curve (identified by the short pink lines) defines the upper and lower 95\% confidence interval limit for the best $\lambda$ value. The interval is $-2.43<\lambda<$ -0.3 and does not include $\lambda=1$ (Fig. 13), thus ensuring that transformation will be helpful. Design-Expert 7.1 software recommends using the power transformation for the best fit of the model although one cannot rule out $\log$, square root, inverse square root, or inverse transformation, as these all fall within the 95\% confidence region. The current recommended transformation is at $\lambda=1$ (indicated by blue line), which is a power transformation and is quite near to the best transformation at $\lambda=-1.39$.

Table 8 gives R-squared values of data for different models. The "R-squared" value near to one always indicates that a regression line fits the data well. The suggested model for the data is linear, with the "adjusted R-squared" value of 0.9974 and "predicted R-Squared" value of 0.9966 , with the p-value (Prob > F) $<0.0001$. After elimination of the insignificant terms, the modified ANOVA is shown in Table 9.

In the new model, the overall F-test value is improved to $1,547.724$ and remains significant with 42 degrees of freedom. Therefore, the modified model has all the significant terms. In the individual factors, the strongest influence on the coefficient of friction is found to be due to the "A-type of treatment" (with the highest $F$ value of 8,175 ), followed by load. The value of different tests under the coefficient of regression analysis was determined and compared as shown in Table 10. The "predicted R-squared" value of 0.9965 is in reasonable agreement with the "adjusted R-squared" value of 0.9973 in this model. The reduced cubic model has an Adeq precision of 149.70, which is better than the full linear model, and much higher than the minimum required value of four. The model can be used to navigate the design space, where the power

Table 8 R-Squared values for different models in the case of coefficient of friction.

\begin{tabular}{cccccc}
\hline Source & Standard deviation & R-squared & Adjusted R-squared & Predicted R-squared & PRESS \\
\hline Linear & $4.44 \mathrm{E}-03$ & 0.903 & 0.8983 & 0.8913 & $3.67 \mathrm{E}-03$ \\
2FI & $1.60 \mathrm{E}-03$ & 0.9884 & 0.9869 & 0.9846 & $5.20 \mathrm{E}-04$ \\
Quadratic & $1.42 \mathrm{E}-03$ & 0.991 & 0.9896 & 0.9876 & $4.19 \mathrm{E}-04$ \\
Cubic & $7.10 \mathrm{E}-04$ & 0.9981 & 0.9974 & 0.9966 & $1.15 \mathrm{E}-04$ \\
\hline
\end{tabular}


Table 9 Modified ANOVA for the coefficient of friction.

\begin{tabular}{|c|c|c|c|c|c|c|}
\hline Source & Sum of squares & $\mathrm{DF}$ & Mean square & $F$ value & p-value Prob $>F$ & \\
\hline Model & 0.033706 & 42 & 0.000803 & 1547.724 & $<0.0001$ & Significant \\
\hline$A$-type of treatment & 0.025435 & 6 & 0.004239 & 8175.511 & $<0.0001$ & Significant \\
\hline$B$-load & 0.003596 & 1 & 0.003596 & 6935.531 & $<0.0001$ & Significant \\
\hline$C$-sliding velocity & 0.001468 & 1 & 0.001468 & 2831.016 & $<0.0001$ & Significant \\
\hline$A B$ & 0.000828 & 6 & 0.000138 & 266.2975 & $<0.0001$ & Significant \\
\hline$A C$ & 0.002028 & 6 & 0.000338 & 652.0205 & $<0.0001$ & Significant \\
\hline$B C$ & $2.82 \mathrm{E}-05$ & 1 & $2.82 \mathrm{E}-05$ & 54.47658 & $<0.0001$ & Significant \\
\hline$B^{2}$ & $6.59 \mathrm{E}-05$ & 1 & $6.59 \mathrm{E}-05$ & 127.0982 & $<0.0001$ & Significant \\
\hline$C^{2}$ & $1.95 \mathrm{E}-05$ & 1 & $1.95 \mathrm{E}-05$ & 37.66527 & $<0.0001$ & Significant \\
\hline$A B C$ & $3.89 \mathrm{E}-05$ & 6 & $6.48 \mathrm{E}-06$ & 12.5059 & $<0.0001$ & Significant \\
\hline$A B^{2}$ & 0.000162 & 6 & $2.71 \mathrm{E}-05$ & 52.20676 & $<0.0001$ & Significant \\
\hline$A C^{2}$ & $2.59 \mathrm{E}-05$ & 6 & $4.32 \mathrm{E}-06$ & 8.325649 & $<0.0001$ & Significant \\
\hline$B^{3}$ & $9.02 \mathrm{E}-06$ & 1 & $9.02 \mathrm{E}-06$ & 17.4038 & $<0.0001$ & Significant \\
\hline Residual & $6.84 \mathrm{E}-05$ & 132 & $5.19 \mathrm{E}-07$ & & & \\
\hline Corrected total & 0.033774 & 174 & & & & \\
\hline
\end{tabular}

Table 10 Coefficients of regression for the full and modified cubic models from ANOVA analysis.

\begin{tabular}{ccccc}
\hline Full linear model & & & \multicolumn{2}{c}{ Reduced linear model } \\
\cline { 1 - 1 } Coefficient of regression & Value & & Coefficient of regression & Value \\
\hline Standard deviation & 0.00071 & & Standard deviation & 0.19 \\
Mean & 0.190205 & Mean & 0.38 \\
C.V. $\%$ & 0.37331 & C.V. $\%$ & $1.18 \mathrm{E}-04$ \\
PRESS & 0.000115 & PRESS & 0.998 \\
R-squared & 0.998074 & R-squared & 0.9973 \\
Adjusted R-squared & 0.997403 & Adjusted R-squared & 0.9965 \\
Predicted R-squared & 0.996593 & Predicted R-squared & Adeq precision & 149.705 \\
Adeq precision & 147.8705 & Ad &
\end{tabular}

of the coefficient of friction can be expressed by the following final regression equations:

Type of treatment: A3T

$\left(\mu_{\mathrm{a}}\right)^{1}=(+0.25-6.15 E-004 \times B-2.17 E-003 \times C-$ $4.27 E-005 \times B \times C+4.55 E-006 \times B^{2}-7.082 E-003 \times$ $\left.C^{2}-1.67 E-008 \times B^{3}\right)$

Type of treatment: ATC1(6)T

$\left(\mu_{\mathrm{a}}\right)^{1}=(+0.25-9.37 E-004 \times B+0.01 \times C-9.29 E-005$ $\times B \times C+6.84 E-006 \times B^{2}-3.49 E-003 \times C^{2}-1.67 E-$ $\left.008 \times B^{3}\right)$

Type of treatment: ATC1(21)T

$\left(\mu_{\mathrm{a}}\right)^{1}=(+0.25-1.03 E-003 \times B+6.27 E-003 \times C-$
$7.46 E-005 \times B \times C+7.19 E-006 \times B^{2}-1.86 E-003 \times$ $\left.C^{2}-1.67 E-008 \times B^{3}\right)$

Type of treatment: ATC1(36)T

$\left(\mu_{\mathrm{a}}\right) 1=(+0.27-1.32 E-003 \times B+4.95 E-004 \times C-$ $2.96 E-005 \times B \times C+8.49 E-006 \times B^{2}-6.83 E-004 \times$ $\left.C^{2}-1.67 E-008 \times B^{3}\right)$

Type of treatment:ATC2(6)T

$\left(\mu_{\mathrm{a}}\right)^{1}=(+0.20-5.24 E-004 \times B-7.60 E-004 \times C+$ $5.41 E-006 \times B \times C+4.83 E-006 \times B^{2}-3.48 E-004 \times$ $\left.C^{2}-1.67 E-008 \times B^{3}\right)$

Type of treatment: ATC2(21)T

$\left(\mu_{\mathrm{a}}\right)^{1}=(+0.20-5.24 E-004 \times B-7.61 E-004 \times C+$ 
$5.41 E-006 \times B \times C+4.82 E-006 \times B^{2}-3.48 E-004 \times$ $\left.C^{2}-1.67 E-008 \times B^{3}\right)$

\section{Type of treatment: ATC2(36)T}

$\left(\mu_{\mathrm{a}}\right) 1=(+0.20-5.24 E-004 \times B-7.61 E-004 \times C+$ $5.41 E-006 \times B \times C+4.83 E-006 \times B^{2}-3.48 E-004 \times$ $\left.C^{2}-1.67 E-008 \times B^{3}\right)$

The validation of Eqs. (8)-(14) is confirmed by comparing the trends of experimental values of the average coefficient of friction in the wear test experiments with the corresponding theoretical values obtained from the ANOVA analysis of the model (Fig. 14) at varying sliding speeds and loads. The graphs demonstrate similar experimental and theoretical results with an average error of $3 \%$ in the corresponding values. This confirms the validation of the model equations obtained for the average coefficient of friction from this analysis and is thus acceptable.
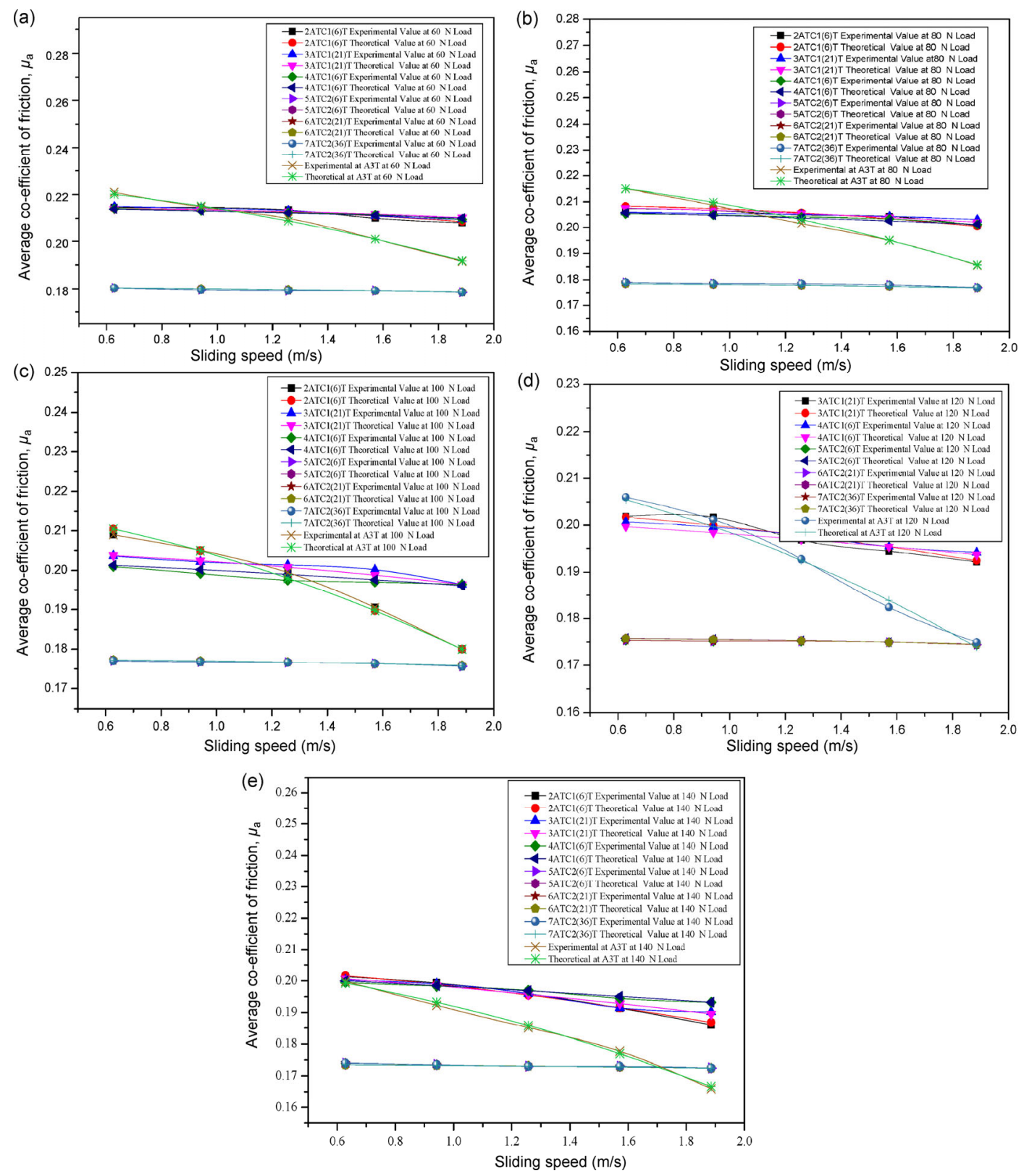

Fig. 14 Comparison of the theoretical and experimental results for the average coefficient of friction during the wear test at varying sliding speeds and loads: (a) $60 \mathrm{~N}$, (b) $80 \mathrm{~N}$, (c) $100 \mathrm{~N}$, (d) $120 \mathrm{~N}$, and (e) $140 \mathrm{~N}$ in the case of various treatments: A3T, ATC1(6)T, ATC1(21)T, ATC1(36)T, ATC2(6)T, ATC2(21)T, and ATC2(36)T. 


\subsection{Evaluation of the maximum contact temperature during the dry sliding condition for HDS AISI H13}

Figure15 presents a distribution of the residuals for this analysis, and indicates that the residuals follow a normal distribution. Figure 16 illustrates the diagnosis of the internally studentized residuals versus the experimental run order for the case of contact temperature. This plot presents the random scatter in the range of \pm 3 standard deviations and all the points are well fitted in the model. The random scatter is found within the range of \pm 3 standard deviation for internally studentized residuals. The process has the similar trend about the mean line and is stable, which proves the acceptability of the model and shows that the model satisfies the assumption for the ANOVA. Figure 17 represents the actual versus the predicted response values for the case of contact temperature. It indicates the adequacy of the model over the range of data; as all the data points are scattered about the 45 degree diagonal reference line.
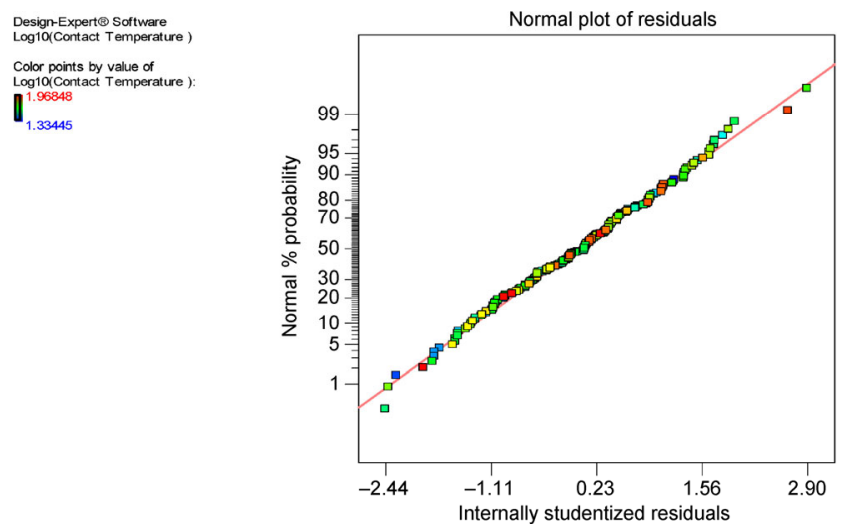

Fig. 15 Normal plot of residuals for maximum contact temperature.

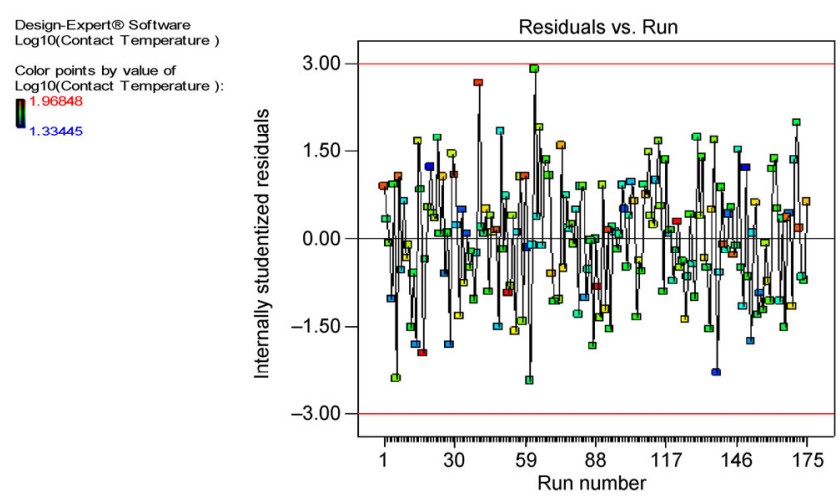

Fig. 16 Distribution of residuals over the experimentation run order for maximum contact temperature.

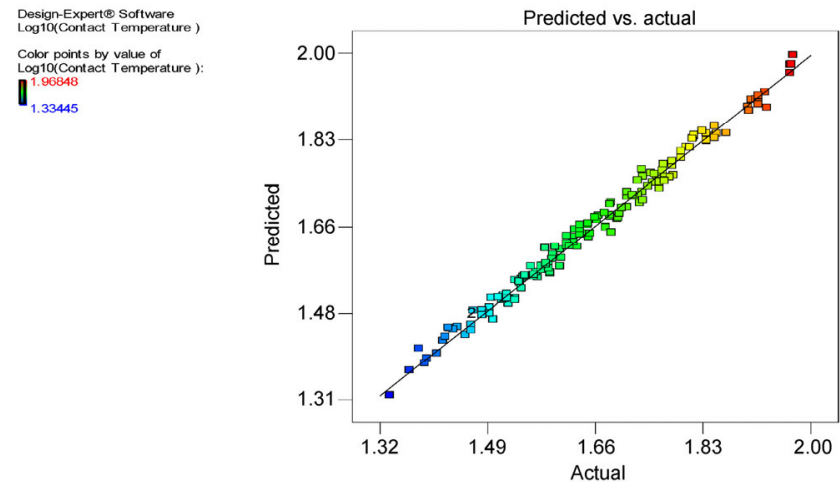

Fig. 17 Predicted as a function of actual response values for maximum contact temperature.

In this case, the response of contact temperature to the input variables varies from the minimum value of 21.6 to 93.0. The ratio of maximum to minimum is 4.30 , which is well within the threshold limit of 10 , therefore, does not indicate the preference of transformation. To further confirm this, the Box-Cox method was used to determine the power transformation for the dependent variable. Figure 18 shows the Box-Cox plot within \pm 3 standard deviations. The legend information on the left of Fig. 18 indicates that the minimum in $\operatorname{Ln}$ (Residual SS) occurs when $\lambda=-0.08$, the best $\lambda$ value indicated in the plot by the long vertical (green line) at the center of the U-shaped curve. The point where the solid horizontal line cuts the U-shaped curve (identified by short pink lines) defines the upper and lower $95 \%$ confidence interval limit for the best $\lambda$ value. The interval is $-0.36<\lambda<0.19$ and does not include the $\lambda=1$ (Fig. 18), thus ensuring that the transformation will be helpful. Design-Expert 7.1 software recommends the log transformation $(\lambda=0)$
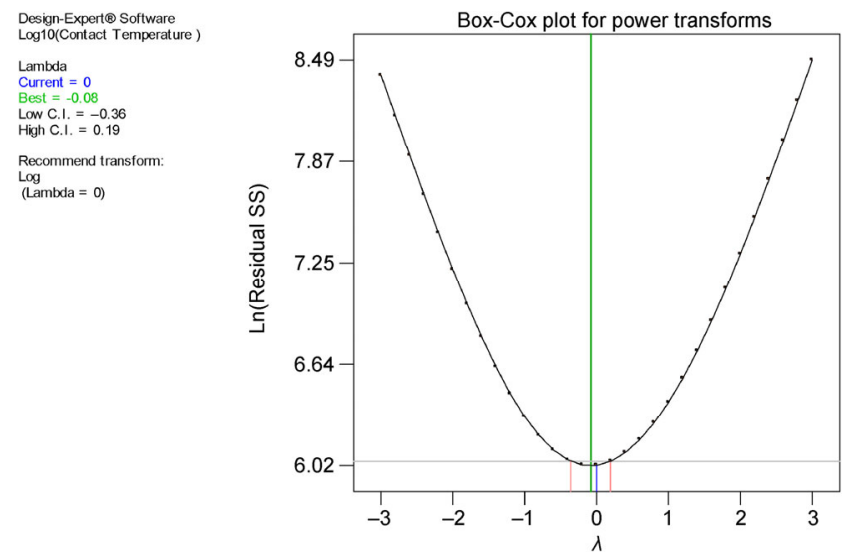

Fig. 18 Box-Cox plot for power transformation in the case of maximum contact temperature. 
for the best fit of the model although one cannot rule out linear, cubic, quadratic and square root, transformation, as all these fall within the $95 \%$ confidence region. The short vertical blue line in Fig. 18 at $\lambda=0$ indicates the current transformation, which is quite near to the best-suggested transformation at $\lambda=-0.08$. The R-squared values of data for different models obtained using Design-Expert 7.1 software are shown in Table 11. The "R-squared" value near to one always indicates that a regression line fits the data well. The suggested model for the data is cubic, with the "adjusted R-squared" value of 0.9905 and "predicted R-squared" value of 0.9840, with the p-value (Prob > $F)<0.0001$. To obtain a more desirable model, all insignificant terms are eliminated and the ANOVA is modified accordingly, as shown in Table 12. In the new model, the overall F-test value is improved to 481.2 and remains significant with 30 degrees of freedom. Therefore, the modified model has all the significant terms, i.e., $A, B, C, A B, A C, B C, B C^{2}$, and $A B^{2}$. In the individual factors, the strongest influence on the contact temperature is found to be due to $C$ : sliding velocity (with the highest $F$ value of 9,760.87), followed by load and treatment type. The next significant influencing effects among the interaction are due to $B$ : load, $A$ : type of treatment, and $A B$. In the second order term, the strongest influence is found to be that of $B C^{2}$.

The values for different tests under the coefficient of regression analysis are determined and compared as shown in Table 13. The "predicted R-squared" value of 0.9844 is in reasonable agreement with the "adjusted R-squared" value of 0.9881 in this model. The reduced quadratic model has an Adeq precision of 98.502, which is better than the full cubic model, and much higher than the minimum required value of four. The model can be used to navigate the design space, where the log of contact temperature can be expressed by the

Table 11 R-Squared values for different models in case of maximum contact temperature.

\begin{tabular}{cccccc}
\hline Source & Standard deviation & R-squared & Adjusted R-squared & Predicted R-squared & PRESS \\
\hline Linear & $7.30 \mathrm{E}-03$ & 0.9325 & 0.9292 & 0.9245 & $9.89 \mathrm{E}-03$ \\
2FI & $5.37 \mathrm{E}-03$ & 0.9663 & 0.9617 & 0.9532 & $6.13 \mathrm{E}-03$ \\
Quadratic & $4.66 \mathrm{E}-03$ & 0.975 & 0.9712 & 0.9645 & $4.65 \mathrm{E}-03$ \\
Cubic & $3.30 \mathrm{E}-03$ & 0.9893 & 0.9856 & 0.9789 & $2.76 \mathrm{E}-03$ \\
\hline
\end{tabular}

Table 12 Modified ANOVA for maximum contact temperature.

\begin{tabular}{|c|c|c|c|c|c|c|}
\hline Source & Sum of Squares & $\mathrm{DF}$ & Mean Square & $F$ Value & p-value Prob $>F$ & \\
\hline Model & 3.85 & 30 & 0.13 & 481.2 & $<0.0001$ & Significant \\
\hline$A$-type of treatment & 0.062 & 6 & 0.01 & 38.43 & $<0.0001$ & Significant \\
\hline$B$-load & 1.56 & 1 & 1.56 & 5827 & $<0.0001$ & Significant \\
\hline$C$-sliding velocity & 2.07 & 1 & 2.07 & 7751.78 & $<0.0001$ & Significant \\
\hline$A B$ & 0.11 & 6 & 0.019 & 69.9 & $<0.0001$ & Significant \\
\hline$A C$ & 0.018 & 6 & $3.05 \mathrm{E}-03$ & 11.42 & $<0.0001$ & Significant \\
\hline$B C$ & 0.013 & 1 & 0.013 & 50.19 & $<0.0001$ & Significant \\
\hline$B^{2}$ & $4.95 \mathrm{E}-04$ & 1 & $4.95 \mathrm{E}-04$ & 1.85 & 0.1755 & \\
\hline$C^{2}$ & $2.09 \mathrm{E}-03$ & 1 & $2.09 \mathrm{E}-03$ & 7.81 & 0.0059 & Significant \\
\hline$A B^{2}$ & 0.014 & 6 & $2.25 \mathrm{E}-03$ & 8.44 & $<0.0001$ & Significant \\
\hline$B C^{2}$ & $7.50 \mathrm{E}-03$ & 1 & $7.50 \mathrm{E}-03$ & 28.09 & $<0.0001$ & Significant \\
\hline Residual & 0.038 & 144 & $2.67 \mathrm{E}-04$ & & & \\
\hline Corrected total & 3.89 & 174 & & & & \\
\hline
\end{tabular}


Table 13 Values of coefficient for full and modified quadratic models from ANOVA analysis.

\begin{tabular}{cccc}
\hline Full linear model & & \multicolumn{2}{c}{ Reduced linear model } \\
\cline { 4 - 4 } \cline { 4 - 4 } Coefficient of regression & Value & Coefficient of regression & Value \\
\hline Standard deviation & 0.015 & Standard deviation & 0.016 \\
Mean & 1.65 & Mean & 1.65 \\
C.V. \% & 0.88 & C.V. \% & 0.99 \\
PRESS & 0.062 & PRESS & 0.061 \\
R-squared & 0.9930 & R-squared & 0.9901 \\
Adjusted R-squared & 0.9905 & Adjusted R-squared & 0.9881 \\
Predicted R-squared & 0.9840 & PredictedR-squared & 0.9844 \\
Adeq precision & 89.217 & Adeq precision & 98.502 \\
\hline
\end{tabular}

following final regression equations:

\section{Type of treatment: A3T}

$\log _{10}\left(T_{\mathrm{M}}\right)=(+1.04+3.43-003 \times B-0.10 \times C+4.22 E-$ $003 \times B \times C-9.43 E-006 \times B^{2}+0.12 \times C^{2}-1.40 E-003$

$\left.\times B \times C^{2}\right)$

\section{Type of treatment: ATC1(6)T}

$\log _{10}\left(T_{\mathrm{M}}\right)=(+1.20+7.52 E-004 \times B-0.09 \times C+4.22 E$

$-003 \times B \times C+1.04 E-006 \times B^{2}+0.12 \times C^{2}-1.40 E-$

$\left.003 \times B \times C^{2}\right)$

\section{Type of treatment: ATC1(21)T}

$\log _{10}\left(T_{\mathrm{M}}\right)=(+1.14+4.29 E-003 \times B-0.16 \times C+4.22 E$ $-003 \times B \times C-1.66 E-005 \times B^{2}+0.12 \times C^{2}-1.40 E-$ $\left.003 \times B \times C^{2}\right)$

\section{Type of treatment: ATC1(36)T}

$\log _{10}\left(T_{\mathrm{M}}\right)=(+1.37+2.59 E-004 \times B-0.13 \times C+4.22 E$ $-003 \times B \times C-5.01 E-006 \times B^{2}+0.12 \times C^{2}-1.40 E-$ $\left.003 \times B \times C^{2}\right)$

\section{Type of treatment: ATC2(6)T}

$\log _{10}\left(T_{\mathrm{M}}\right)=(+1.64-6.01 E-003 \times B-0.15 \times C+4.22 E$

$-003 \times B \times C+2.73 E-005 \times B^{2}+0.12 \times C^{2}-1.40 E-$ $\left.003 \times B \times C^{2}\right)$

\section{Type of treatment: ATC2(21)T}

$\log _{10}\left(T_{\mathrm{M}}\right)=(+1.26+1.07 E-003 \times B-0.13 \times C+4.22 E$ $-003 \times B \times C-5.65 E-006 \times B^{2}+0.12 \times C^{2}-1.40 E-$ $\left.003 \times B \times C^{2}\right)$

\section{Type of treatment: ATC2(36)T}

$\log _{10}\left(T_{\mathrm{M}}\right)=(+1.04+3.40 E-003 \times B-0.10 \times C+$ $4.227 E-003 \times B \times C-9.30 E-006 \times B^{2}+0.12 \times C^{2}-$ $\left.1.40 E-003 \times B \times C^{2}\right)$
The validation of Eqs. (15)-(21) is confirmed by comparing the trends of experimental values of temperature at the junction of the block sample with the ring and with the corresponding theoratical values obtained from the ANOVA analysis of the (Fig. 19) at varying sliding speeds and loads. The graphs show similar experimental and theoratical results, with an average error of $8 \%$ in the corresponding values. This confirms the validation of the model equations obtained for contact temperature from this analysis and is thus acceptable.

It is observed that as the sliding velocity varies from $0.628 \mathrm{~m} / \mathrm{s}$ to $1.885 \mathrm{~m} / \mathrm{s}$, the maximum contact temperature increases (from $21.6{ }^{\circ} \mathrm{C}$ to $93.0{ }^{\circ} \mathrm{C}$ ) for selected loads (60-140 N) for the conventionally treated and all types of cryogenically treated material under investigation. As the temperature increases, the $W_{R}$ decreases.

The effects of macroscopic temperature on wear behavior of friction pairs were evaluated using the relationship of sliding velocity and Peclet number (Pe). The Peclet number (Pe) for this study ranges from 0.86 to 7.7 , which is less than 10. As the sliding velocity, or Pe increases, the maximum surface contact temperature decreases due to the transfer of heat to the moving mass.

While the front edge of the moving mass approaches the heat supply source, it is at a lower surface temperature in comparison to the heat source. The thermal diffusivity and heat capacity of the material is finite. Hence, to take in heat and to increase its temperature, this requires time. With the increase in moving mass 

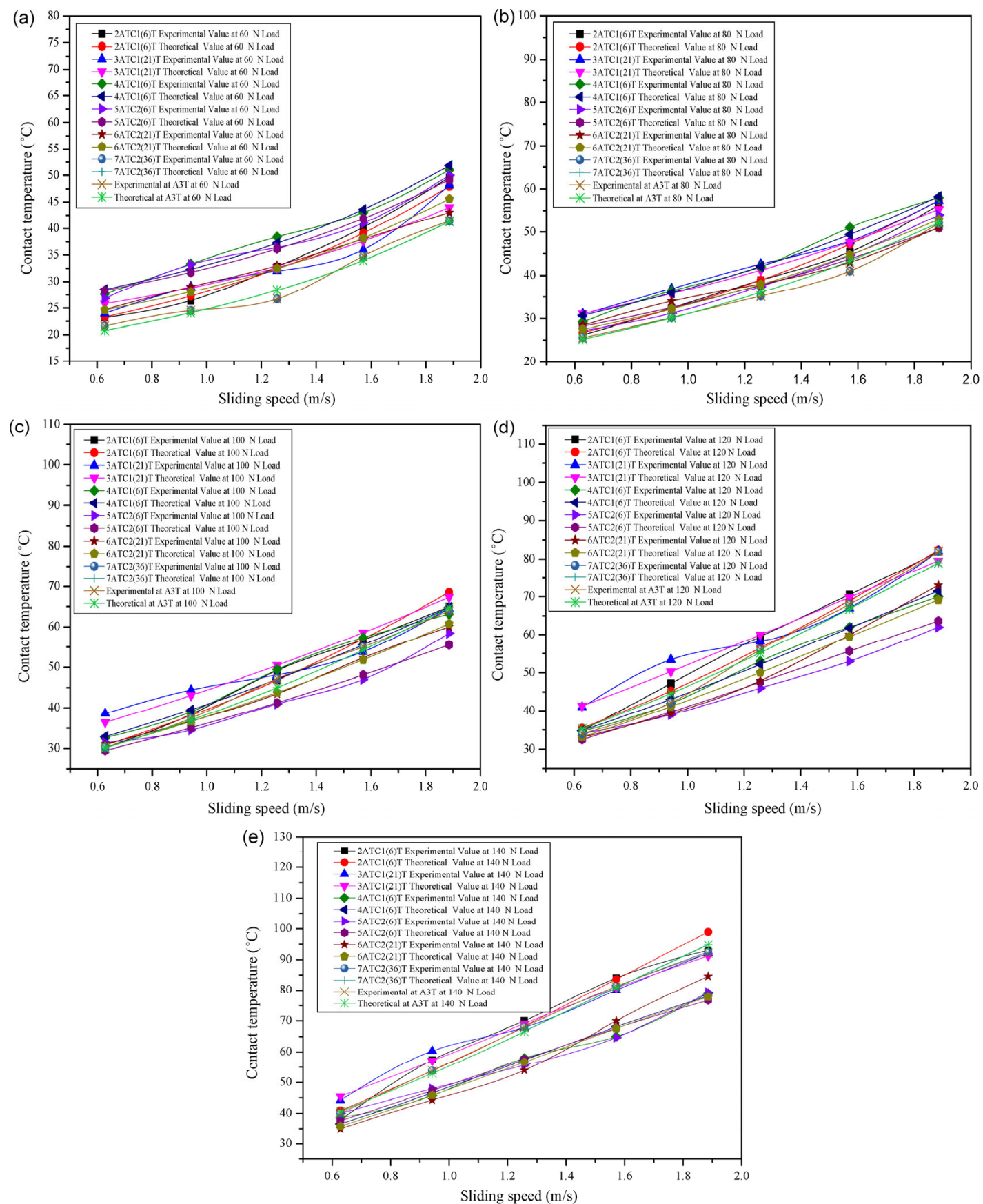

Fig. 19 Comparison of the theoratical and experimental results for the rise in contact temperature during the wear test at varying sliding speeds and loads: (a) $60 \mathrm{~N}$, (b) $80 \mathrm{~N}$, (c) $100 \mathrm{~N}$, (d) $120 \mathrm{~N}$, and (e) $140 \mathrm{~N}$ in the case of various treatments: A3T, ATC1(6)T, ATC1(21)T, ATC1(36)T, ATC2(6)T, ATC2(21)T, and ATC2(36)T.

velocity, it spends less time underneath the heat source for a specific volume of material. Thus, the increase in temperature will be less [21].

\section{Optimization}

The desirability function approach of the RSM technique has been used in this study to determine the optimum parameters to achieve a low value of $W_{R}$ average coefficient of friction, and maximum contact temperature. This study has three different responses for the variables, each of which is modeled with a different polynomial equation. The model for $W_{R}$ is a natural $\log$, the model for the average coefficient 
of friction is linear and the model for the contact temperature is a natural log. Accordingly, each will have a different graph with different optimal factor settings. The values of the variables with maximum total desirability are considered to be optimal parameter conditions. The ranges and goals of each input process parameter and measured response (optimization criterion) are provided in Table 14, which is used to minimize the rate of wear, average coefficient of friction, and contact temperature, with the highest desirability function for the optimized setting for the desired output response.

The default value of " 1 " for the weight is assigned to the variables to achieve the maximum desirability function by giving equal weight to all goals. Considering the importance of each variable value given in Table 14, a set of 24 optimal solutions with the highest desirability function are obtained within the specifically designed space constraints. Table 14 illustrates the optimized results for minimizing the tribological parameters by considering seven combinations of categorical factor levels and the results are summarized in Table 15.

Further, conformity tests are carried out under the same conditions to validate the adequacy of the mathematical correlations. The objective of the confirmation experiments is to demonstrate the validity of the mathematical model derived from a designed experiment. The average of the results from the confirmation experiment is compared with the predicted average based on the parameters and levels tested, as shown in Table 16, which illustrates that the experimental values are in reasonable agreement with the predicted response values. The variations between the experimental and the predicted results are of the order of $2 \%-9 \%$.

3D plots for desirability are constructed to consider the different possible combinations of the numeric variables as load and sliding velocity at the abscissa

Table 14 Constraints for determining the optimum values of the tribological parameters.

\begin{tabular}{|c|c|c|c|}
\hline Parameter & Goal & Weight & Importance \\
\hline Type of treatment $(A)$ & $\mathrm{A} 3 \mathrm{~T} \leqslant A \leqslant \mathrm{ATC}(36) \mathrm{T}$ & 1 & 3 \\
\hline $\operatorname{Load}(B), \mathrm{N}$ & $60 \leqslant B \leqslant 140$ & 1 & 3 \\
\hline Sliding velocity $(C), \mathrm{m} / \mathrm{s}$ & $0.628 \leqslant C \leqslant 1.885$ & 1 & 3 \\
\hline Wear rate, $W_{\mathrm{R}}(D), \mathrm{gm} / \mathrm{m}$ & $1.69 \times 10^{-5} \leqslant D \leqslant 1.48 \times 10^{-4}$ & 1 & 5 \\
\hline Average coefficient of friction $(E)$ & $0.16 \leqslant E \leqslant 0.22$ & 1 & 3 \\
\hline Contact temperature $(F),{ }^{\circ} \mathrm{C}$ & $21.6 \leqslant F \leqslant 93$ & 1 & 3 \\
\hline
\end{tabular}

Table 15 Optimization results for the tribological parameters.

\begin{tabular}{ccccccc}
\hline $\begin{array}{c}\text { S. } \\
\text { No. }\end{array}$ & $\begin{array}{c}\text { Type of } \\
\text { treatment, }(A)\end{array}$ & $\begin{array}{c}\text { Load }(B), \\
\mathrm{N}\end{array}$ & $\begin{array}{c}\text { Sliding velocity } \\
(C), \mathrm{m} / \mathrm{s}\end{array}$ & $\begin{array}{c}W_{\mathrm{R}}(D), \\
\mathrm{g} / \mathrm{m}\end{array}$ & $\begin{array}{c}\text { Average coefficient } \\
\text { of friction, }(E)\end{array}$ & $\begin{array}{c}\text { Contact temperature } \\
(F),{ }^{\circ} \mathrm{C}\end{array}$ \\
\hline 1 & ATC2(21)T & 60 & 0.687 & $1.73 \mathrm{E}-06$ & 0.18 & 26.46 \\
Desirability
\end{tabular}

Table 16 Results of the conformity tests for the tribological parameters.

\begin{tabular}{|c|c|c|c|c|c|c|c|c|c|c|c|c|}
\hline \multirow{2}{*}{$\begin{array}{l}\text { Test } \\
\text { No. }\end{array}$} & \multicolumn{3}{|c|}{ Process parameter } & \multicolumn{3}{|c|}{$\begin{array}{l}\text { Response parameter } \\
\text { (predicted value) }\end{array}$} & \multicolumn{3}{|c|}{$\begin{array}{l}\text { Response parameter } \\
\text { (experimental value) }\end{array}$} & \multicolumn{3}{|c|}{$\%$ Error } \\
\hline & $\begin{array}{l}\text { Treatment } \\
\text { type }\end{array}$ & $\begin{array}{c}B \\
(\mathrm{~N})\end{array}$ & $\begin{array}{c}C \\
(\mathrm{~m} / \mathrm{s})\end{array}$ & $\begin{array}{c}W_{\mathrm{R}} \\
(\mathrm{gm} / \mathrm{m})\end{array}$ & $\mu_{\mathrm{a}}$ & $\begin{array}{c}T_{\mathrm{M}} \\
\left({ }^{\circ} \mathrm{C}\right) \\
\end{array}$ & $\begin{array}{c}W_{\mathrm{R}} \\
\mathrm{gm} / \mathrm{m}\end{array}$ & $\mu_{\mathrm{a}}$ & $\begin{array}{c}T_{\mathrm{M}} \\
\left({ }^{\circ} \mathrm{C}\right) \\
\end{array}$ & $\begin{array}{c}W_{\mathrm{R}} \\
(\mathrm{gm} / \mathrm{m})\end{array}$ & $\mu_{\mathrm{a}}$ & $\begin{array}{l}T_{\mathrm{M}} \\
\left({ }^{\circ} \mathrm{C}\right) \\
\end{array}$ \\
\hline 1 & $\operatorname{ATC} 2(21) \mathrm{T}$ & 60 & 0.687 & $1.73 \mathrm{E}-06$ & 0.18 & 26.46 & $1.88 \mathrm{E}-06$ & 0.18 & 24.5 & 8.67 & 2.08 & 7.41 \\
\hline 2 & ATC2(21)T & 60 & 0.682 & $1.73 \mathrm{E}-06$ & 0.18 & 26.41 & $1.83 \mathrm{E}-06$ & 0.19 & 27.4 & 5.78 & 2.63 & 3.73 \\
\hline 3 & $\operatorname{ATC} 2(21) \mathrm{T}$ & 60 & 0.696 & $1.73 \mathrm{E}-06$ & 0.18 & 26.54 & $1.80 \mathrm{E}-06$ & 0.19 & 24.9 & 4.04 & 3.19 & 6.18 \\
\hline
\end{tabular}


(Fig. 20(a)), keeping all the response variables at the minimum to achieve the maximum possible life. The chosen categorical factor is ATC2(21)T following the result as shown in Table 15. Respective contour plots of desirability as a function of sliding velocity and loads are shown in Fig. 20(b). It can be interpreted from Figs. 20(a) and 20(b) that the overall desirability value is less in the region of the higher value of the load and sliding velocity. The desirability value is higher at the lower load and sliding velocity. The contour plot of Fig. 20(b) shows the sensitivity of the results to the condition. The optimal region was located in the lower left-side of the plot closer to the smaller values of the applied load and sliding velocity, represented by the maximum value of the predicted desirability (red colored region), which is 0.89 . This region displayed overall the greatest desirability of 0.89 at the center. The change in color of the region while moving away from the highest desirability point indicates a gradual reduction of the desirability. The sensitivity of the response is also indicated by the shape of the contour lines in Fig. 20(b).

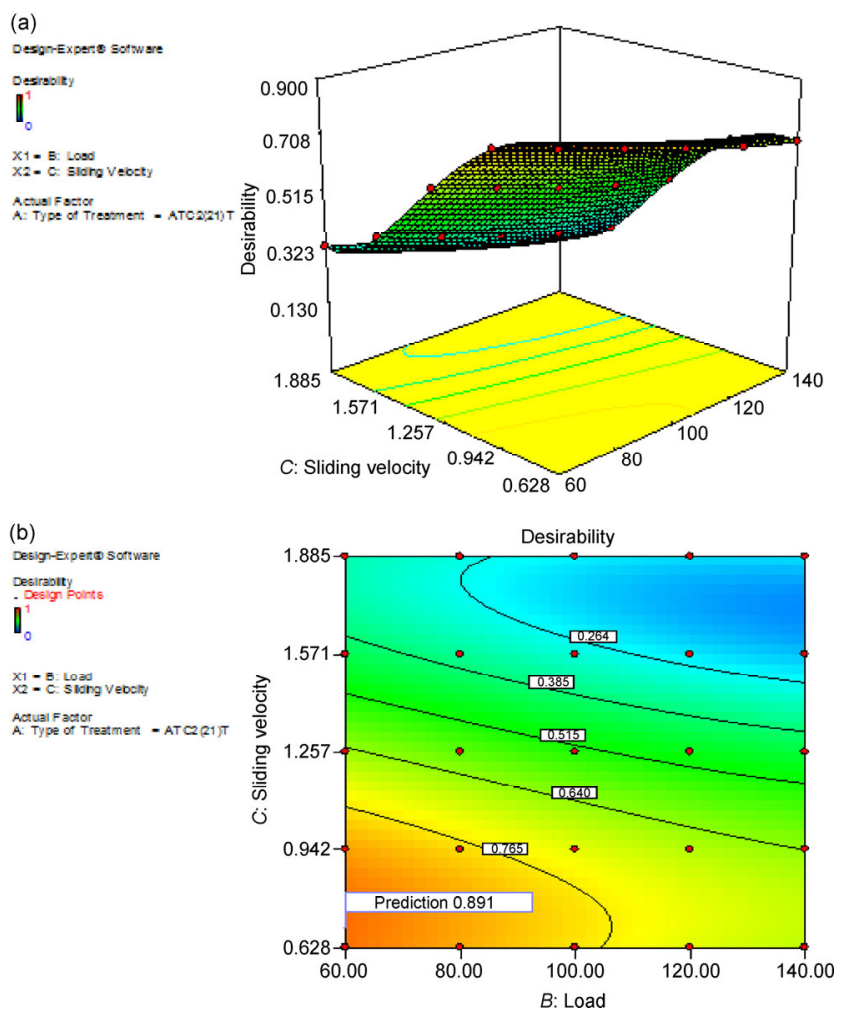

Fig. 20 (a) 3D plot, (b) contour plot for desirability versus sliding velocity and load.

\section{Conclusions}

In this study, mathematical models have been proposed to predict the tribological behavior $\left(W_{\mathrm{R}}\right.$, the average coefficient of friction $\left(\mu_{\mathrm{a}}\right)$, and the maximum contact temperature $\left(T_{\mathrm{M}}\right)$ ) of varied cryogenically treated HDS H13 against cold-work steel AISI D3 under a different set of operating parameters. Furthermore, optimal conditions are identified for the minimum $W_{R}$. The major conclusions drawn from this study are:

The present study demonstrates that the soaking time of $21 \mathrm{~h}$ at $-184^{\circ} \mathrm{C}$ for HDS H13, is the optimum soak time to have the maximum wear resistance.

The parameter sliding velocity $(C)$ influences the $W_{\mathrm{R}}$ more in comparison to the second parameter load (B). The first parameter of the study (type of treatment) treatment ATC2(21)T gives the optimal set of conditions possessing the highest desirability value $(0.891)$ and is selected for the desired response, which is: load: $60 \mathrm{~N}$; sliding velocity: $0.687 \mathrm{~m} / \mathrm{s} ; W_{\mathrm{R}}: 1.73 \times 10^{-4} \mathrm{gm} / \mathrm{m}$; average coefficient of friction $\left(\mu_{\mathrm{a}}\right): 0.18$; and maximum contact temperature: $26.46{ }^{\circ} \mathrm{C}$.

The CT enhances the wear resistance of HDS H13 in comparison to the CHT, up to the holding time of $21 \mathrm{~h}$ at $-184{ }^{\circ} \mathrm{C}$, beyond this it shows a decrease with further increase in the soak time.

The morphology of worn surfaces of cryogenically treated samples changes from mild to severe as the sliding velocity and applied load increases in the chosen set of parameters for the experiment.

Wear debris has the shape of a plate-form of metal and appeared to delaminate from the samples surface due to sub-surface cracks and plastic deformation.

An average error of $9 \%, 3 \%$, and $8 \%$ exists in the experimental and theoretical results obtained using the model equations for $W_{R}$, the average coefficient of friction $\left(\mu_{\mathrm{a}}\right)$ and the maximum contact temperature $\left(T_{\mathrm{M}}\right)$ respectively.

The experimental values are in reasonable agreement with the predicted response values in the case of optimization. The variations between the experimental and the predicted results are of the order of $8.7 \%$, $3.2 \%$, and $7.4 \%$ for the $W_{R}$, the average coefficient of friction, and the maximum contact temperature, respectively, for the selected optimized treatment type ATC2(21)T. 


\section{Acknowledgement}

The authors gratefully acknowledge their gratitude to the National Institute of Technology, Hamirpur to grant funds for the procurement of the hot die steel material, making available their tribological test; Institute of Auto Parts and Hand tools Technology, Ludhiana for extending facilities under the expert supervision of spectroscopic analysis, vacuum heat treatment and cryogenic treatment facility required for the study.

Open Access: The articles published in this journal are distributed under the terms of the Creative Commons Attribution 4.0 International License (http:// creativecommons.org/licenses/by/4.0/), which permits unrestricted use, distribution, and reproduction in any medium, provided you give appropriate credit to the original author(s) and the source, provide a link to the Creative Commons license, and indicate if changes were made.

\section{References}

[1] Roberts G. Tools Steels. $5^{\text {th }}$ Ed. Materials Park, OH, USA: ASM International, 1998: 46-66.

[2] Lal D M, Renganarayanan S, Kalanidhi A. Cryogenic treatment to augment wear resistance of tool and die Steel. Cryogenics 41: 149-55 (2001)

[3] Barron R F. Effects of cryogenic treatment on lath tool wear. Progress in Refrigeration Science and Technology, Publishing Co. Westport 1: 529-34 (1973)

[4] Das D, Dutta A K, Ray K K. Sub-Zero treatments of AISI D2 Steel: Part I. Microstructure and hardness. Mater Sci Eng A 527: 2182-2193 (2010)

[5] Mehtedi M E, Ricci P, Drudi L, Mohtadi S E, Cabibbo M, Spigarelli S. Analysis of the effect of deep cryogenic treatment on the hardness and microstructure of X30CrMoN 151 steel. Mater Design 33: 136-144 (2012)

[6] Koneshlou M, Meshinchi K, Khomamizadeh F. Effect of cryogenic treatment on microstructure, mechanical and wear behaviors of AISI H13 hot work tool steel. Cryogenics 51: 55-61 (2011)

[7] Katoch S, Sehgal R, Singh V. Effect of cryogenic treatment on hardness, microstructure and wear behavior of hot die steel grade AISI-H13. In Proceeding of International
Conference on Advances in Tribology and Engineering Systems, 2014: 159-166.

[8] Amini K, Nategh S, Shafyei A. Influence of different cryotreatments on tribological behavior of $80 \mathrm{CrMo} 125$ cold work tool steel. Mater Design 31: 4666-4675 (2010)

[9] Das D, Dutta A K, Ray K K. Influence of varied cryo-treatment on the wear behavior of AISI D2 steel. Wear 266: 297-309 (2009)

[10] Gunes I, Cicek A, Aslantas K, Kara F. Effect of deep cryogenic treatment on wear resistance of AISI 52100 bearing steel. Trans Indian Inst Met 67: 909-917 (2014)

[11] Yong A Y L, Seah K H W, Rehman M. Performance of cryogenically treated tungsten carbide tools in milling operations. Int J Adv Manuf Technol 32: 638-643 (2007)

[12] Firouzdor V, Nejati E, Khomamizadeh F. Effect of deep cryogenic treatment on wear resistance and tool life of M2 HSS drill. J Mater Process Technol 206: 467-472 (2008)

[13] Huang Y, Zhu Y T, Liao X Z, Beyerlein I J, Bourlce M A, Mitchell T E, Microstructure of cryogenic treated M2 Tool Steel. Mater Sci Eng A 339: 241-244 (2003)

[14] ASTM E 415-2014. Standard test method for Analysis of carbon and low alloy steel by spark atomic emission spectrometry. ASTM Annual Book of Standards. West Conshohocken, PA, United States.

[15] Bayer A M, Vasco T, Walton L R. Properties and selection: Iron, steels and high performance alloys. ASM Handbook, 3rd ed. ASM International, Materials Park, OH, USA, 1995.

[16] ASTM E10-2010. Standard test method for Brinell hardness of metallic materials. ASTM Annual Book of Standards. West Conshohocken, PA, United States, 2010: 91-122.

[17] ASTM G77-2010. Standard test method for ranking resistance of materials to sliding wear using block-on-ring wear test. ASTM Annual Book of Standards. West Conshohocken, PA, United States.

[18] ASTM E384-08a (2009). Standard test method for micro indentation hardness of materials. ASTM Annual Book of Standard, Vol. 3.01. West Conshohocken, PA, United States.

[19] George F Vander Voort. Metallography and microstructure. ASM Handbook, 9th ed. ASM International, Materials Park, OH, USA, 1995: 257-263.

[20] Suh N P. An overview of the delamination theory of wear. Wear 44:1-16 (1977)

[21] Sharma M D, Sehgal R, Pant M. Tribological behavior of Ti3A12.5V alloy against EN-31 steel under dry condition. Tribol Trans 59(3): 451-461 (2016) 


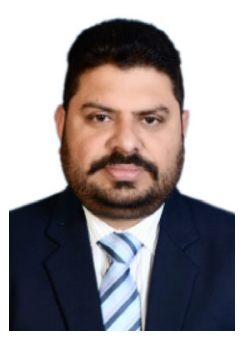

Sanjeev KATOCH. He was graduated in science from Government Degree Collage Hamirpur, Himachal Pradesh University, Shimla, India in 1993. He obtained his master degree in materials science from Thapar University, Patiala, Punjab, India in 1997. He is currently pursuing his Ph.D. degree in the Center for Materials Science \& Engineering, National Institute of Technology, Hamirpur, Himachal Pradesh, India. Along with his research work, he is working as deputy manager (Testing \& Evaluation and Heat

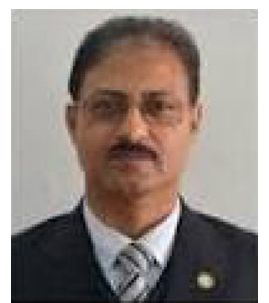

Rakesh SEHGAL. He is a professor in the Department of Mechanical Engineering at National Institute of Technology (Institute of higher learning-Government of India), Hamirpur, Himachal Pradesh, India. He obtained his M.Tech. degree in design of mechanical equipment from Indian Institute of Technology, Delhi, India, and received his $\mathrm{PhD}$ degree in mechanical engineering from Kurukshetra University, Kurukshetra, India in 2001. Dr. Sehgal has also completed his Post-Doctorate under PDF Award scheme of University Grants Commission, Ministry of Human Resource Development, Govt. of India.

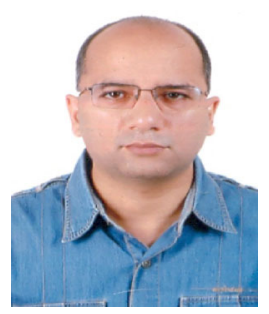

Vishal SINGH. He is presently an associate professor at the Centre for Materials Science and Engineering, National Institute of Technology (Institute of higher learningGovernment of India), Hamirpur, Himachal Pradesh, India. He received a B.E. degree in metallurgical engineering from University of Roorkee, Roorkee, India in 1992, an $\mathrm{M}$. Tech. degree in metallurgical engineering from Indian Institute of Technology (IIT), Bombay, India in treatment Department) with Institute for Auto Parts \& Hand Tools Technology, Ludhiana, Punjab, India. He has 18 years of experience in the heat treatment of materials, testing, evaluation of auto component \& tool material through metallurgical, and mechanical \& NDT techniques. His area of research/ interest is cryogenic processing of materials, tribological behavior of tools and dies, and failure analysis and nondestructive evaluation of materials and components. He has several publications in various reputed journals and international conference proceedings.

His research interest includes tribology, reliability modeling, and machining and optimization of production systems. He has two years of field and 25 years of teaching and research experience. He has published in journals such as Transactions of the ASME, Journal of Tribology, Tribology International, Tribology Online, Proc. IMechE Part B: Journal of Engineering Manufacture, International Journal for Manufacturing Science \& Production, International Journal of Precision and Manufacturing, International Journal of Production Economics, Journal of Reliability \& Systems Safety, Journal of Intelligent Manufacturing, Materials and Manufacturing Processes, Applied Acoustics, Journal of Vibration and Acoustics, among others.

1995 and a Ph.D. degree from Indian Institute of Technology (IIT), Bombay, India in 2003. His research interests include electrical, mechanical, and tribological behavior of polymer composites/ nano-composites, physical metallurgy, and ceramic processing and characterization. He has more than twelve years of research and teaching experience in materials science related areas and his research work has been published in several international journals and conference proceedings of repute. 